\title{
Localized precipitation and runoff on Mars
}

\author{
Edwin S. Kite, ${ }^{1,2}$ Timothy I. Michaels, ${ }^{3}$ Scot Rafkin, ${ }^{3}$ Michael Manga, ${ }^{1,2}$ \\ and William E. Dietrich ${ }^{1}$ \\ Received 3 December 2010; revised 2 March 2011; accepted 20 April 2011; published 13 July 2011.
}

[1] We use the Mars Regional Atmospheric Modeling System (MRAMS) to simulate lake storms on Mars, finding that intense localized precipitation will occur for lake size $\geq 10^{3} \mathrm{~km}^{2}$. Mars has a low-density atmosphere, so deep convection can be triggered by small amounts of latent heat release. In our reference simulation, the buoyant plume lifts vapor above condensation level, forming a $20 \mathrm{~km}$ high optically thick cloud. Ice grains grow to $200 \mu \mathrm{m}$ radius and fall near (or in) the lake at mean rates up to $1.5 \mathrm{~mm} \mathrm{~h}^{-1}$ water equivalent (maximum rates up to $6 \mathrm{~mm} \mathrm{~h}^{-1}$ water equivalent). Because atmospheric temperatures outside the surface layer are always well below $273 \mathrm{~K}$, supersaturation and condensation begin at low altitudes above lakes on Mars. In contrast to Earth lake-effect storms, lake storms on Mars involve continuous precipitation, and their vertical velocities and plume heights exceed those of tropical thunderstorms on Earth. For lake sizes $10^{2.5}$ to $10^{3.5} \mathrm{~km}$, plume vertical velocity scales linearly with lake area. Convection does not reach above the planetary boundary layer for lakes $\ll 10^{3} \mathrm{~km}^{2}$ or for atmospheric pressure $>\mathrm{O}\left(10^{2}\right)$ mbar. Instead, vapor is advected downwind with little cloud formation. Precipitation occurs as snow, and the daytime radiative forcing at the land surface due to plume vapor and storm clouds is too small to melt snow directly $\left(<+10 \mathrm{~W} \mathrm{~m}^{-2}\right)$. However, if orbital conditions are favorable, then the snow may be seasonally unstable to melting and produce runoff to form channels. We calculate the probability of melting by running thermal models over all possible orbital conditions and weighting their outcomes by probabilities given by long-term integrations of the chaotic diffusion of solar system orbital elements. With this approach, we determine that for an equatorial vapor source, sunlight $15 \%$ fainter than at present and snowpack with albedo $0.28(0.35)$, melting may occur with $4 \%(0.1 \%)$ probability. This rises to $56 \%(12 \%)$ if the ancient greenhouse effect was modestly $(6 \mathrm{~K})$ greater than today.

Citation: Kite, E. S., T. I. Michaels, S. Rafkin, M. Manga, and W. E. Dietrich (2011), Localized precipitation and runoff on Mars, J. Geophys. Res., 116, E07002, doi:10.1029/2010JE003783.

\section{Introduction}

[2] Evidence for runoff on Mars shows it to have been patchy in both space and time [Kraal et al., 2008; Williams, 2007; Weitz et al., 2008; Fassett and Head, 2008a; Hynek et al., 2010; Carr and Malin, 2000], so perhaps past precipitation was also patchy [Gulick and Baker, 1989]. Because patchy surface vapor sources cannot persist in equilibrium with a dry atmosphere [Richardson and Soto, 2008; Soto and Richardson, 2008], vapor would have to be supplied from an environment not in equilibrium with surface conditions. Such environments can be transient, such as an impact lake, or long-lived, such as the base of a wet-based ice sheet. They can be high-temperature, such as fumaroles (or a lava flow

\footnotetext{
${ }^{1}$ Department of Earth and Planetary Science, University of California, Berkeley, California, USA.

${ }^{2}$ Center for Integrative Planetary Science, University of California, Berkeley, California, USA.

${ }^{3}$ Department of Space Studies, Southwest Research Institute, Boulder, Colorado, USA.

Copyright 2011 by the American Geophysical Union. 0148-0227/11/2010JE003783
}

advancing over snowpack), or involve only moderate temperatures, such as groundwater discharge. Liquid water has been present on the surface (though out of equilibrium) intermittently over a broad interval of Mars history. For example, groundwater discharges have occurred at least from the Late Noachian through Early Amazonian [Carr and Head, 2010]. Impacts into icy targets have probably formed short-lived impact lakes throughout Martian history.

[3] Here we use a mesoscale model to explore the atmospheric response to one example of a nonequilibrium vapor source: an ephemeral lake on a cold desert Mars. We track the fate of vapor supplied by the lake from release, through cloud formation, to precipitation, and consider whether the resulting snow will melt and produce runoff. Lake size, solar luminosity, lake geometry, and atmospheric pressure all affect the results. Only idealized results are presented: a companion paper (E. S. Kite et al., Valles Marineris chaos, storms and past climate on Mars, submitted to Journal of Geophysical Research, 2010, hereafter paper 2) uses the same model for a case study of the Juventae plateau inverted channel networks [Weitz et al., 2008].

[4] Low volumetric heat capacity makes the Mars atmosphere's response to lake vapor release similar to tropical 


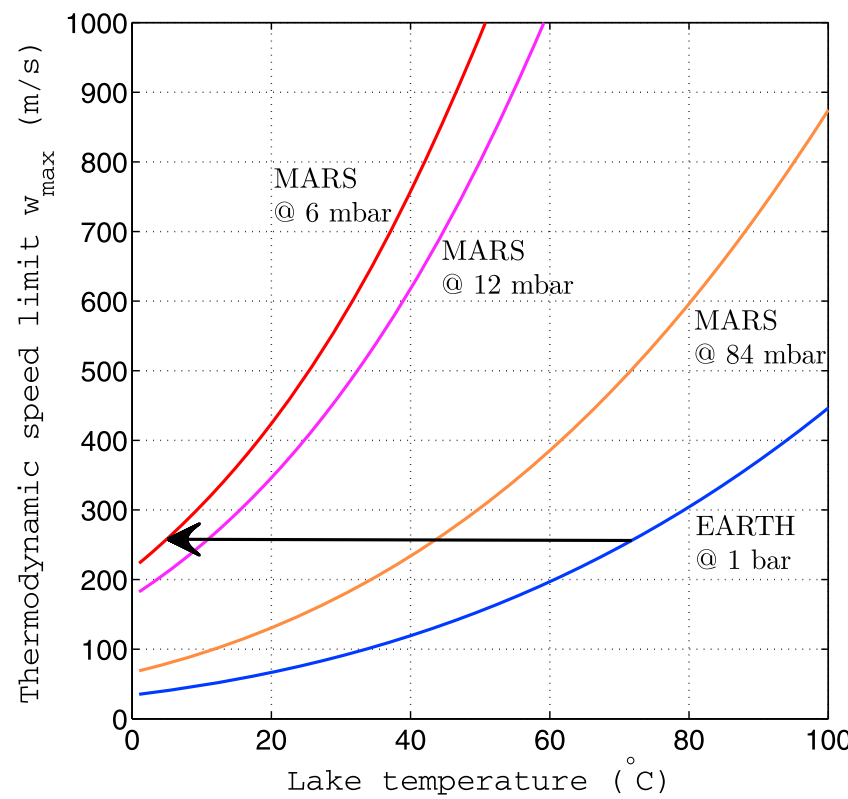

Figure 1. Dependence of lake-driven convection on lake temperature and atmospheric pressure. Moist convection is enhanced on low-pressure Mars relative to 1 bar Earth because more buoyancy is produced for a given sea surface temperature or lake surface temperature. One measure of the strength of convection is the maximum vertical velocity of an updraft $w_{\max }$ $(=\sqrt{2 \mathrm{CAPE}}$, where CAPE is convective available potential energy), the so-called thermodynamic speed limit [Markowski and Richardson, 2010]. Suppose the level of free convection (LFC) to be at the surface and the equilibrium level (EL) at $1.5 \mathrm{~km}$ for both planets. Suppose complete isobaric condensation and precipitation of a parcel at 50\% humidity at the surface. In an otherwise dry atmosphere, and neglecting some second-order thermodynamic corrections, $w_{\max }$ is then as shown. The red curve is for today's Mars, the blue curve is for today's Earth, and the magenta curve is the pressure used in our Mars simulations. The black arrow shows that convection above a $5^{\circ} \mathrm{C}$ lake on Mars may be as vigorous as above a $72^{\circ}$ lake on Earth. The orange curve corresponds to the threshold pressure above which we suspect localized precipitation on Mars does not occur. Values used are $c_{\mathrm{p}, \text { Mars }}=$ $770 \mathrm{~J} \mathrm{~kg}^{-1} ; c_{\mathrm{p}, \text { Earth }}=1003 \mathrm{~J} \mathrm{~kg}^{-1} ; R_{\text {Earth }}=287 \mathrm{~J} \mathrm{~K}^{-1} \mathrm{~mol}^{-1}$; $R_{\text {Mars }}=189 \mathrm{~J} \mathrm{~K}^{-1} \mathrm{~mol}^{-1} ; g_{\text {Mars }}=3.7 \mathrm{~m} \mathrm{~s}^{-2} ; g_{\text {Earth }}=9.8 \mathrm{~m} \mathrm{~s}^{-2}$; latent heat of sublimation $L_{\mathrm{s}} \sim$ latent heat of evaporation $L_{\mathrm{e}} \sim$ $2.5 \times 10^{6} \mathrm{~J} \mathrm{~kg}^{-1}$; saturation vapor pressure curve from Hardy [1998].

moist convection on Earth, so we borrow ideas from tropical meteorology to understand our results [e.g., Emanuel, 1994]. Figure 1 shows the low-pressure lake effect: condensation of a small amount of vapor in a thin atmosphere can produce strong convection, which in Earth's thick atmosphere would require condensation of a large amount of vapor and correspondingly high water surface temperatures.

[5] Localized precipitation on a cold desert planet is normally transient precipitation. A warm, wet patch connected to the global atmosphere will lose water to cold traps elsewhere on the planet [Richardson and Soto, 2008]; the water table will withdraw to the subsurface because of evaporative losses
[Soto and Richardson, 2008]. In the absence of an external heat source, evaporative and radiative cooling will cause any lake to quickly freeze [Lorenz et al., 2005; Conway et al., 2011]. (These arguments do not apply to springs, nor proglacial discharge of subglacial meltwater. In these cases, under cold conditions, any given parcel of water will freeze over, but a sustained vapor source can nevertheless exist at the discharge site.) As the ice thickens, ice surface temperature will fall and the correspondingly lower saturation vapor pressure will cause the rate of vapor release to greatly decrease. For realistic external heat sources, the lake lifetime is still short. For example, consider an impact-generated lake near the freezing point overlying shocked basalt that is initially at $1000^{\circ} \mathrm{C}$. The lake is assumed to be well mixed by waves driven by lake-effect and impact thermal storms, and convection driven by bottom heating. Icing over is inevitable when the heat flow from the interior of the lake toward the surface is less than the evaporative and radiative losses at the surface. The maximum time before icing over, $t$, is therefore

$$
t \approx \frac{D\left(T_{\mathrm{b}}-T\right) c_{\mathrm{b}} \rho_{\mathrm{b}}}{\left(E L_{\mathrm{v}}+\sigma T^{4}\right)}
$$

where $D$ is the depth of pervasive fracturing within the rock ejecta, $T_{\mathrm{b}}=1273 \mathrm{~K}$ is the initial temperature of the basalt, $T=$ $278.15 \mathrm{~K}$ is lake surface temperature, $c_{\mathrm{b}}=840 \mathrm{~J} \mathrm{~kg}^{-1} \mathrm{~K}^{-1}$ the specific heat capacity of the basalt, $\rho_{\mathrm{b}}=2000 \mathrm{~kg} / \mathrm{m}^{3}$ the density of the fractured basalt, $L_{\mathrm{v}} \approx 2.5 \times 10^{5} \mathrm{~J} \mathrm{~kg}^{-1}$ the latent heat of vaporization, and $\sigma=5.67 \times 10^{-8} \mathrm{Wm}^{-2} \mathrm{~K}^{-4}$ is the Stefan-Boltzmann constant. From the results in this paper (Table 2), we set the evaporation rate $E=2 \mathrm{~kg} \mathrm{~m}^{-2} \mathrm{~h}^{-1}$. We choose $T=278.15 \mathrm{~K}$ because it is just above the temperature of maximum density of pure water at $277.14 \mathrm{~K}$; below this temperature the lake surface will quickly freeze. For $D=$ $100 \mathrm{~m}$ we obtain $\sim 4$ Earth years: a geological instant. The true timescale will be less. For example, if fractures within the ejecta anneal, the relevant timescale is conductive cooling of a half-space (the ejecta layer) by an isothermal boundary condition (the well-mixed lake) until the heat flow into the bottom of the lake is less than heat loss at the top of the lake [Turcotte and Schubert, 2002]:

$$
t \approx\left(\frac{k\left(T_{\mathrm{b}}-T\right)}{E L_{\mathrm{v}}+\sigma T^{4}}\right)^{2} \frac{1}{(\pi \kappa)}
$$

In this case, the conductive heat flow can only balance evaporative plus radiative losses for $\sim 3$ days for thermal diffusivity $\kappa=10^{-6} \mathrm{~m}^{2} \mathrm{~s}^{-1}$ and thermal conductivity $k=$ $2.5 \mathrm{~W} \mathrm{~m}^{-1} \mathrm{~K}^{-1}$ : after this, an ice cover must form.

[6] Therefore, we are interested in spatially restricted $\left(10^{0}\right.$ to $10^{3} \mathrm{~km}$ ) water sources which cease to emit vapor in timescales $<1$ year. This is the domain of mesoscale modeling. We use the Mars Regional Atmospheric Modeling System (MRAMS), also used for entry, descent and landing simulations for the Mars Exploration Rovers, Mars Phoenix, and Mars Science Laboratory (Appendix A) [Rafkin et al., 2001; Michaels and Rafkin, 2008a]. MRAMS explicitly resolves the size spectrum of dust and water ice aerosol for both cloud microphysics and radiative transfer, so it is well 
suited for our cloud-forming numerical experiments [Michaels and Rafkin, 2008a].

\section{Localized Precipitation on Mars: Order of Magnitude Reasoning}

[7] Consider liquid water at the surface of Mars: the atmospheric temperature is similar to today. The surface is not entirely frozen because drainage or filling stirs the lake and mechanically disrupts the ice cover, convection mines heat from an underlying hot layer to balance evaporative cooling, subsurface discharge outpaces evaporation, or fumaroles and gas-charged fountains inject vapor and small droplets directly to the atmosphere. The injection rate is approximately [Emanuel, 1994]

$$
Q_{h} \approx C_{D}\left|V_{a}\right|\left(r_{s}^{*}-r_{b}\right)
$$

where $C_{D} \approx 10^{-3}$ is a surface exchange coefficient [Emanuel, 1994 , p. 484], $V_{a} \approx 10 \mathrm{~m} \mathrm{~s}^{-1}$ is anemometer-level wind speed, $r_{s}{ }^{*} \approx 0.5$ is the near-surface vapor mixing ratio, and $r_{b} \simeq 0$ is the background water vapor mixing ratio. To convert this to the vapor mixing ratio in air that enters the buoyant plume, we require a length scale (a vertical distance over which the vapor is mixed) and a timescale (during which the vapor is injected). A reasonable length scale is the thickness of the subcloud layer $\Delta Z_{\mathrm{sc}} \approx 2 \mathrm{~km}$. A reasonable timescale is the fetch timescale $t_{\mathrm{f}}=D_{\text {lake }} /\left|V_{a}\right| \approx 2 \mathrm{~h}$ for a $65 \mathrm{~km}$ lake (where $D_{\text {lake }}$ is lake diameter). This gives a vapor mixing ratio in air that enters the buoyant plume, $r \approx 0.01 \equiv 6 \mathrm{~Pa}$.

[8] Convection initiation is made more likely by Mars' low atmospheric temperatures. Air containing $6 \mathrm{~Pa}$ vapor will be supersaturated with respect to ice when $\mathrm{T}<227 \mathrm{~K}$ [Hardy, 1998]. Mars today has an atmospheric surface layer $20 \mathrm{~K}$ on average colder than its ground surface temperature (European Mars Climate Database v4.3, described by Lewis et al. [1999] and Millour et al. [2008], hereafter European Mars Climate Database). For example, at $\mathrm{L}_{s}=255^{\circ}$ (near perihelion) the latitudinal maximum in zonally averaged diurnal maximum surface temperature is $304 \mathrm{~K}$, but the zonal mean daily maximum atmospheric surface layer temperature at this latitude is only $265 \mathrm{~K}$. This offset is due to the low atmospheric column density, because (for fixed atmospheric compositional mixing ratios and assuming the atmosphere to be optically thin in the thermal IR) this reduces radiative and mechanical coupling between the atmosphere and surface [Pierrehumbert, 2010]. In the current climate, diurnal mean equatorial atmospheric temperature is below $227 \mathrm{~K}$ at all altitudes and all times of the year (European Mars Climate Database). Because of these low temperatures, supersaturation of the vapor (and nucleation and growth via deposition) occurs close to the ground. On Earth, the strongest lake storms are associated with rare cold air outbreaks and large air-lake temperature contrasts [Markowski and Richardson, 2010]. For Mars, assuming the atmosphere is similar to the present Mars atmosphere, a large air-lake temperature contrast will occur for ephemeral lakes that form at any season and any latitude.

[9] Mars' low atmospheric pressure promotes deep convection (Figure 1). Because of the low volumetric heat capacity, we assume that the plume will accelerate upward until $90 \%$ of the vapor has crystallized. Assuming that no precipitation occurs, and using an empirical lapse rate of $\Gamma \sim 1.5 \mathrm{~K} \mathrm{~km}^{-1}$ (from the European Mars Climate Database) and the Clapeyron slope for ice at $230 \mathrm{~K}$, this occurs $12 \mathrm{~km}$ above cloud base.

[10] During this ascent, the plume will have gained convectively available potential energy (CAPE):

$$
\mathrm{CAPE} \approx \rho_{\mathrm{a}} g \int_{\mathrm{CB}}^{\mathrm{MC}} \frac{T}{T^{\prime}}-(1+\mu) \mathrm{d} z
$$

where $\rho_{\mathrm{a}}$ is atmospheric density, $g=3.7 \mathrm{~m} \mathrm{~s}^{-2}$ is Mars gravity, $\mathrm{MC}$ is the elevation of almost complete condensation, $\mathrm{CB}$ is cloud base, $T$ is temperature within the plume, $T^{\prime}$ the environmental temperature, and $\mu$ the ice mixing ratio [Rogers and Yau, 1989]. This assumes that there is no precipitation of ice out of the parcel. Approximating the ice crystallization as linear from 0 at $\mathrm{CB}$ to complete at $\mathrm{MC}$, we obtain $T-T^{\prime}=$ $r L_{v} / c_{\mathrm{CO} 2} \sim 30 \mathrm{~K}$ so $T / T^{\prime} \sim 1.15$ upon complete crystallization (here, $c_{\mathrm{CO} 2}$ is specific heat capacity for $\mathrm{CO}_{2}$ ). $\mu \sim 0.01$ can then be set aside as negligible. Thus CAPE gained during ascent $\sim 3000 \mathrm{~J} \mathrm{~kg}^{-1}$ and peak vertical velocity $W_{\max }=$ $\sqrt{2 \mathrm{CAPE} / \rho_{a}} \sim 80 \mathrm{~m} \mathrm{~s}^{-1}$. We have ignored differential pressure gradient acceleration and compensating downward motions [Rogers and Yau, 1989] in obtaining this result. The plume will continue to ascend well above MC, but will decelerate as it entrains more ambient air and spreads to form an anvil cloud. The ascent timescale $t_{\text {ascend }}$ is $12 \mathrm{~km} / 0.5 W_{\max }=$ $300 \mathrm{~s}$. Attention now shifts to the growing ice crystals.

[11] We assume heterogenous nucleation of ice occurs on dust. Equatorial dust opacity $\tau_{\mathrm{d}}$ is typically $0.01-0.05$ during northern summer and 0.1-0.8 during southern summer in the thermal infrared [Liu et al., 2003]. The present-day typical low-latitude effective radius of dust is $\sim 1.6 \mu \mathrm{m}$ [Wolff and Clancy, 2003]. A uniform dust density in the lower $30 \mathrm{~km}$ implies a number density of $4 \times 10^{4} \mathrm{~m}^{-3}$ ice nuclei (considering geometric cross section only and neglecting selfshadowing) for $\tau=0.01$ (or $4 \times 10^{6} \mathrm{~m}^{-3}$ for $\tau=1$ ). At $20 \mathrm{~km}$ elevation ( $3 \mathrm{~g} \mathrm{~m}^{-3}$ air; $0.03 \mathrm{~g} \mathrm{~m}^{-3} \mathrm{H}_{2} \mathrm{O}$ ), this yields a "seeder" crystal radius $r$ of $58 \mu \mathrm{m}$ (or $13 \mu \mathrm{m}$ for $\tau=1$ ), a minimum, in that it assumes all ice nuclei are consumed. Since crystallization is implicit in the updraft-velocity calculation, we do not assign a separate timescale to nucleation and early growth.

[12] How fast will crystals grow to precipitable size? Assuming that the seeder crystals sink relative to the updraft and anvil cloud while scavenging both vapor and smaller droplets, the growth rate is just [Rogers and Yau, 1989]

$$
\frac{\mathrm{d} R}{\mathrm{~d} t} \approx \frac{\bar{E} M}{4 \rho_{\mathrm{i}}} \Delta W
$$

where $\bar{E} \approx 1$ is collection efficiency, $M \approx 0.03 \mathrm{~g} \mathrm{~m}^{-3} \mathrm{H}_{2} \mathrm{O}$ is cloud total water content at $20 \mathrm{~km}, \rho_{\mathrm{i}}=910 \mathrm{~kg} \mathrm{~m}^{-3}$ is ice density, and $\Delta W \approx 10 \mathrm{~m} \mathrm{~s}^{-1}$ is a characteristic sink rate relative to the surrounding vapor-laden air. This gives a growth time $t_{\text {growth }} \approx 2000 \mathrm{~s}$ to precipitable size (assumed $200 \mu \mathrm{m})$. In Earth thunderstorms this also requires tens of minutes.

[13] The crystals now begin to fall. At the low temperatures encountered at high altitudes on Mars, we expect the water 
Table 1. List of Runs With Parameters

\begin{tabular}{|c|c|c|c|c|}
\hline Run & Full Name & Lake Size (pixels) & Description & Deep Moist Convection? \\
\hline DRY & lake_0.005_Mar_7_2010 & - & Control case without lake & - \\
\hline REF & lake_0.000_Jan_10_2010 & $11 \times 11$ & Reference simulation (13 days) & yes \\
\hline LINE & lake_0.001_Jan_10_2010 & $5 \times 149$ & Line source in valley & no \\
\hline $\mathrm{S}$ & lake_0.018_Mar_30_2010 & $1 \times 1$ & Size sensitivity & no \\
\hline M & lake_0.019_Mar_30_2010 & $3 \times 3$ & Size sensitivity & no \\
\hline $\mathrm{L}$ & lake_0.030_May_10_2010 & $7 \times 7$ & Size sensitivity & yes \\
\hline XXL & lake_0.020_Mar_30_2010 & $29 \times 29$ & Size sensitivity & yes \\
\hline ROUGH & lake_0.006_Mar_12_2010 & $11 \times 11$ & Garrett [1992] lake surface roughness & yes \\
\hline LO_SUN & lake_0.023_Apr_16_2010 & $11 \times 11$ & $0.75 \times$ present solar luminosity & yes \\
\hline HIRES & lake_0.004_Feb_10_2010 & $' 11 \times 11 '$ & Horizontal resolution check & yes \\
\hline WINTER & lake_0.000_May_1_2010 & $11 \times 11$ & Seasonal sensitivity $\left(\mathrm{L}_{s}=90^{\circ}\right)$ & yes \\
\hline MIDLAT & lake_0.000_Jun_25_2010 & $11 \times 11$ & Latitude sensitivity (latitude $\sim 45^{\circ}$ ) & yes \\
\hline HIPRESS & lake_0.033_Jul_22_2010 & $11 \times 11$ & 60 mbar atmospheric pressure & no \\
\hline $\mathrm{dz} \_30 \mathrm{~m}$ & afternoon_tzz_test_30m_Jan_11_2010 & $11 \times 11$ & Vertical resolution check & \\
\hline $\mathrm{dz} \_10 \mathrm{~m}$ & afternoon_dz_test_10m_Jan_11_2010 & $11 \times 11$ & Vertical resolution check & \\
\hline $\mathrm{dz} \_3 \mathrm{~m}$ & 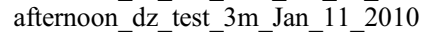 & $11 \times 11$ & Vertical resolution check & \\
\hline $\mathrm{dz} \_1 \mathrm{~m}$ & afternoon_dz_test_1m_Jan_11_2010 & $11 \times 11$ & Vertical resolution check & \\
\hline
\end{tabular}

to form hexagonal cylinders [Wallace and Hobbs, 2006]. The drag coefficient $C_{D}$ for cylinders is $\sim 1$ over a wide range of Reynolds number Re, $10^{2}$ to $10^{5}$ [Tritton, 1988]. Therefore, we obtain a terminal velocity of [Tritton, 1988]

$$
u_{\infty}=\sqrt{\frac{2 g \rho_{i} \pi r}{0.5 \rho_{a}}}
$$

which with $r=200 \mu \mathrm{m}$ gives $40 \mathrm{~ms}^{-1}$. Using the dynamic viscosity of $\mathrm{CO}_{2}$ at $233 \mathrm{~K}, \mu_{\mathrm{a}}=1.2 \times 10^{-7} \mathrm{~Pa}$ s, we obtain $R e=\rho_{a} u_{\infty} r / \mu_{\mathrm{a}} \sim 200$, sustaining the assumption of $10^{2}<R e<$ $10^{5}$. Fall time from anvil cloud height is then $t_{\text {fall }}=H_{\text {plume }} /$ $u_{\infty} \sim 500 \mathrm{~s}$.

[14] The total lifetime of the vapor from release to precipitation as snow is $t=t_{\text {ascend }}+t_{\text {grow }}+t_{\text {fall }} \sim 3000 \mathrm{~s}$. During the entire process of ascent through the plume, crystal growth, and snow fall, the parcel has been blown sideways by the regional winds. Taking $20 \mathrm{~m} \mathrm{~s}^{-1}$ as a representative shear velocity at cloud-forming altitudes of $\sim 20 \mathrm{~km}$ (European Mars Climate Database), we find that snowfall will be roughly $\sim 60 \mathrm{~km}$ downwind of source. This is small compared to the sizes of many Martian geographic features (craters, canyons, volcanoes). Therefore, provided latent heating powers a strong buoyant plume immediately downwind of the lake that lofts the released vapor to a height at which it will condense, we hypothesize that localized precipitation can occur on Mars.

[15] In order to test this hypothesis, we carry out a set of numerical experiments.

\section{Model Setup}

[16] Our numerical experiments used four nested grids with $160 \mathrm{~km}$ resolution on the outermost (hemispheric) grid, increasing to $5.9 \mathrm{~km}$ on the innermost grid. Model vertical layer thicknesses varied from $2.3 \mathrm{~km}$ at altitude to $30 \mathrm{~m}$ near the ground. The lake is centered at $6.5 \mathrm{~S}, 299 \mathrm{E}$ (the location of Juventae Chasma; paper 2).

[17] For these simulations we prescribed flat land at $0 \mathrm{~m}$ on all grids, with uniform albedo $=0.16$, uniform thermal inertia $=290$ kieffers [Mellon et al., 2000], and uniform roughness $z=0.03 \mathrm{~m}$ (the value determined for the Mars
Pathfinder landing site [Sullivan et al., 2000]). We introduced an isothermal lake with albedo $=0.05$, and constant roughness $z=0.01 \mathrm{~m}$, which is close to the time-averaged roughness value obtained with the sea surface roughness parameterization of equation 7.21 of Pielke [2002]. Lake surface temperature is pinned to $278.15 \mathrm{~K}$, with saturation vapor pressure according to Hardy [1998]. Constant lake surface temperature is a reasonable approximation if either (1) the lake is deep and well mixed (e.g., for the $4 \mathrm{~km}$ deep lake at Juventae Chasma, cooling rate $\sim 0.01 \mathrm{~K} \mathrm{~d}^{-1}$ for an evaporation rate of $2 \mathrm{~mm} \mathrm{~h}^{-1}$ if the lake is well mixed) or (2) the lake surface is constantly refreshed by discharge of warm, perhaps gas-charged water from an aquifer [Harrison and Grimm, 2008; Bargery and Wilson, 2010]. In either case, the lake temperature will change more slowly than the (strongly diurnal) atmospheric response. The focus of this first study is to identify the steady state response of the atmosphere to the lake perturbation, so a time-dependent treatment of coupled lake thermodynamics is not appropriate. We use the NASA Ames MGCM [Haberle et al., 1993] to provide atmospheric boundary conditions. To prevent extremely high water substance mixing ratios and to allow metastable surface liquid water at $+2 \mathrm{~km}$ above datum (the elevation of the Juventae plateau streams in paper 2), we double atmospheric pressure relative to today in our simulation by doubling initial and boundary pressures supplied by the GCM. Runs are at $\mathrm{L}_{s} \approx 270^{\circ}$ (southern summer solstice). Runs were for 7 days, except for the REF simulation which was extended to 12 days to test for precipitation variability. Many of these parameters were varied in sensitivity tests: see Table 1 for a list of runs and parameters varied. More details on the model setup are provided in the Appendix.

[18] We carried out a dry run forced by these boundary conditions using flat topography but no lake. In the DRY run, surface pressure is $1190-1270 \mathrm{~Pa}, 40 \%$ more than the saturation vapor pressure at $278.15 \mathrm{~K}$. Surface temperatures range from 209 to $281 \mathrm{~K}$. Surface winds are from the NNE, backing to the north during the passage of each afternoon's thermal tide. Wind direction rotates anticlockwise with increasing height until, near cloud top elevation $(\sim 30 \mathrm{~km}$ in the reference run), wind direction stabilizes at east to ESE (the subtropical jet of Mars' single Hadley cell). There are no significant day- 
a)

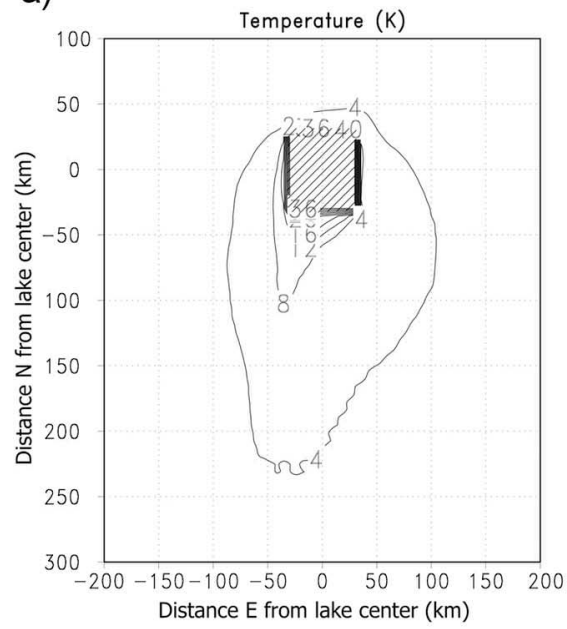

d)

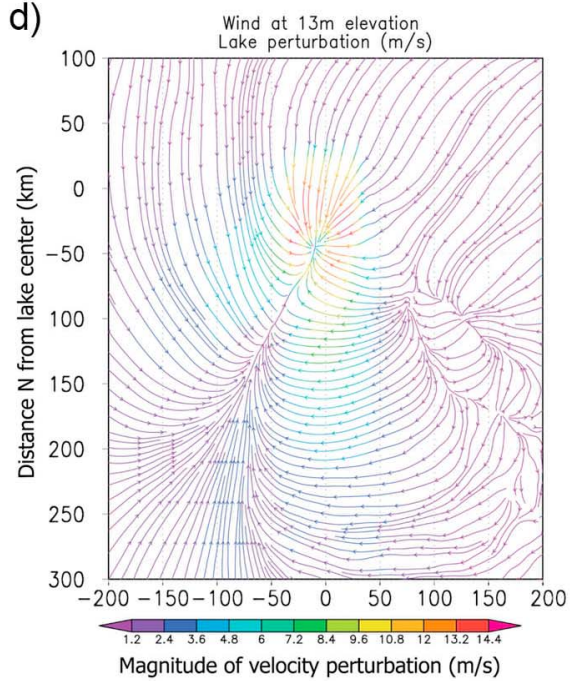

b)

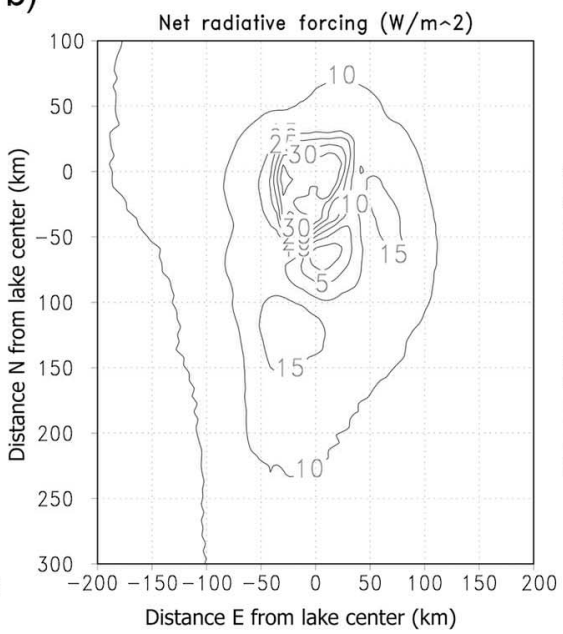

e)

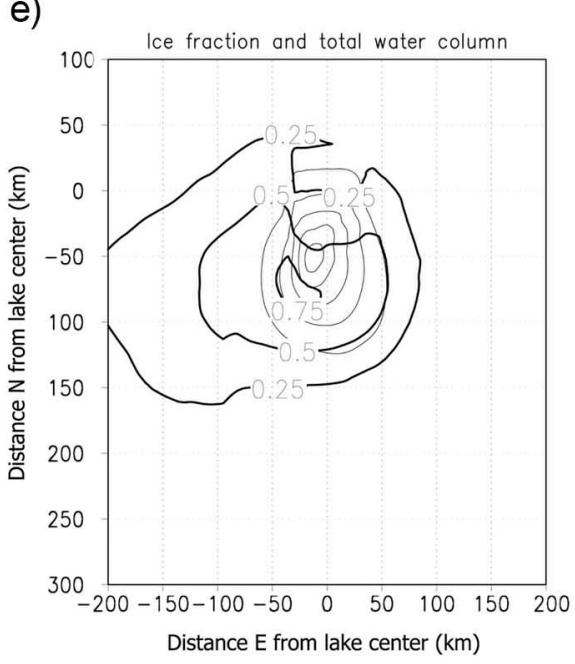

Figure 2. Time-averaged response to the lake (in the map plane). The area shown is a subset of the inmost grid. The shaded area in the Figure 2a shows the extent of the lake. (a) Temperature perturbation due to lake; (b) radiative forcing at the surface; (c) overall surface layer wind field with lake added; (d) perturbation to surface layer wind field due to lake; and (e) total water column abundance (thin lines at spacing of 0.25 precipitable $\mathrm{cm}$ ) and fractional ice abundance (thick lines).

to-day variations in the wind field. The mean $0-6 \mathrm{~km}$ shear is $22 \mathrm{~m} \mathrm{~s}^{-1}$.

\section{Analysis of Reference Simulation}

[19] For our reference simulation, referred to here as REF, we introduce a square lake with sides $\sim 65 \mathrm{~km}$. This is similar to the diameter of Mojave Crater, a young crater with a fluvially modified rim [McEwen et al., 2007; Williams and Malin, 2008]). We begin the analysis by describing the timeaveraged response.

\subsection{Time-Averaged Response}

[20] Because the Mars daily average temperature is below freezing, the lake transfers sensible heat to the atmosphere on average. It also injects radiatively active water vapor into the atmosphere, whose condensation at altitude releases latent heat and produces strongly scattering water ice aerosols.

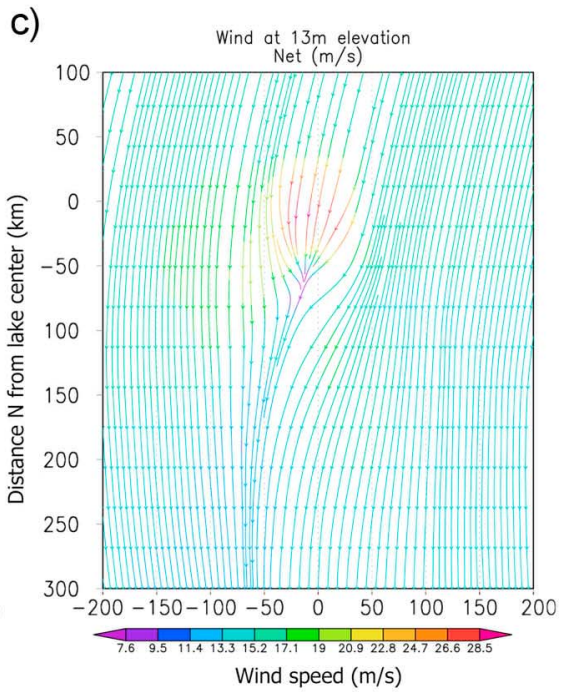




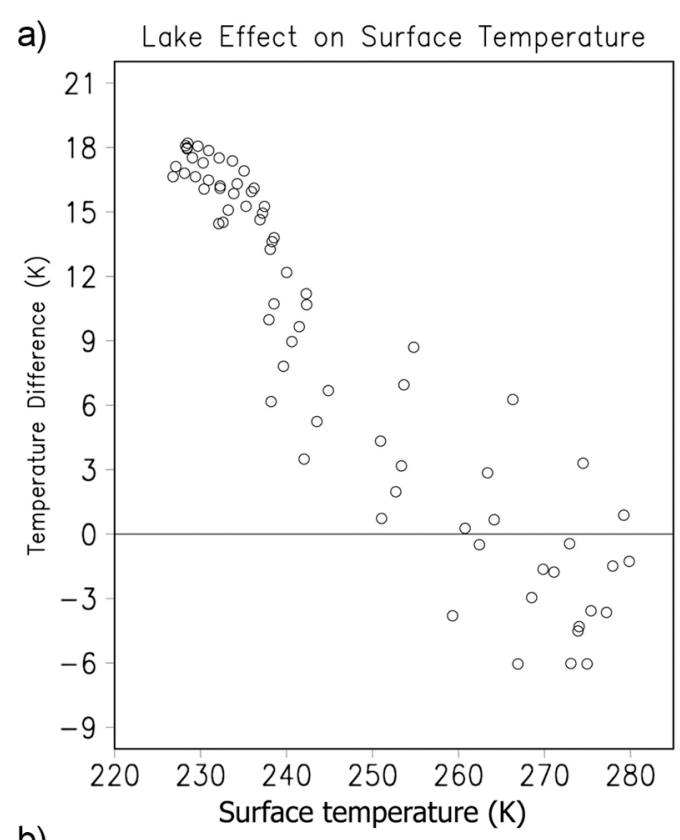

b)

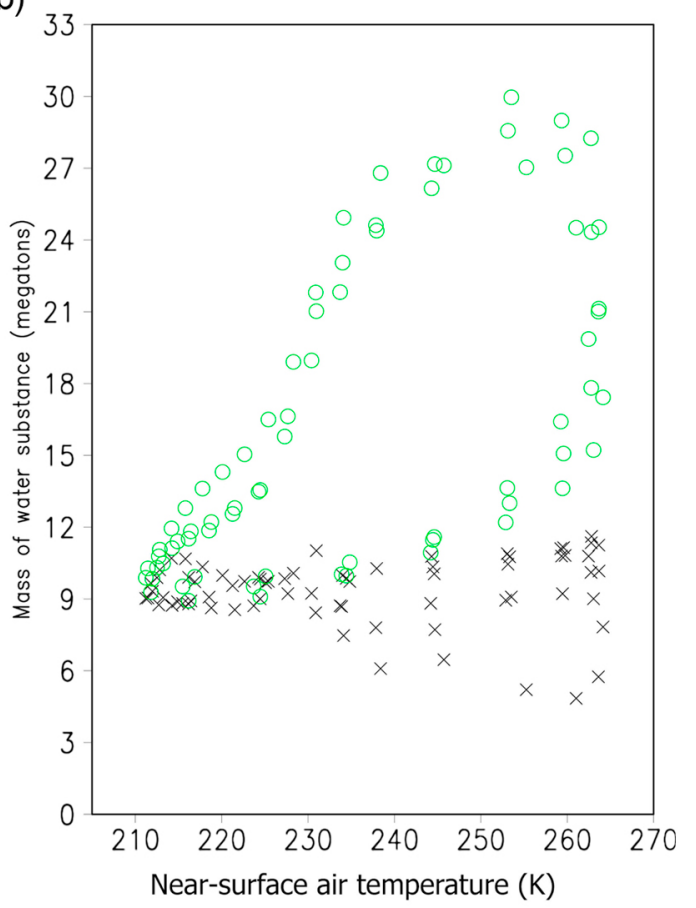

Figure 3. Spatially averaged time dependencies are highly repeatable between sols. (a) Lake perturbation to surface temperature downwind of the lake, as a function of surface temperature in K. (b) Mass of water in atmosphere in a $400 \mathrm{~km}$ side square box centered on the cloud, as a function of near-surface air temperature in K. Green circles correspond to vapor mass, and black crosses correspond to ice mass.

ascending to condensation level; it is modestly positive or slightly negative while vapor is being converted into scatterers; and it becomes positive again when those scatterers have had time (equivalently, distance South) to precipitate out.

[22] A vertical slice through the atmosphere shows three components to the time-averaged atmospheric temperature response to the presence of the lake. Atmospheric tempera- tures in a thin boundary layer above the lake are warmed by $30 \mathrm{~K}$. The planetary boundary layer is thickened downwind of the lake because of the increased turbulence associated with the lake. The surface is warmer than the atmosphere, so that part of the atmosphere that is turbulently coupled to the surface (the planetary boundary layer) is warmer than the overlying atmosphere. As a result, temperatures are higher by $4 \mathrm{~K}$ in that part of the atmosphere that is included in the boundary layer in the lake simulation, but which is not part of the planetary boundary layer in the dry run. Most importantly, a narrow plume of $5-10 \mathrm{~K}$ increased temperatures extends $10-15 \mathrm{~km}$ above the lake. This thermal plume corresponds to the latent heat released by the lake-induced storm. Atmospheric temperatures never exceed $273 \mathrm{~K}$, so liquid water droplets are never stable. Supercooled water droplets are not included in our simulations, and could only form very close to the lake surface.

[23] Strong low-level convergence results from the release of latent heat (Figures $2 \mathrm{c}$ and $2 \mathrm{~d}$ ).

[24] The total water column abundance (thin lines in Figure 2e) shows the narrow extent of the weather system induced by the lake: its core is similar in horizontal extent to a terrestrial thunderstorm. The contours of (ice/total water) fraction (thick lines in Figure 2e) are extended to the west of the lake because the ice-rich uppermost levels of the cloud are affected by the Easterly subtropical jet. Resublimation within this jet lowers the ice fraction with increasing distance to the west.

\subsection{Spatially Averaged Time Dependencies}

[25] The area of peak water-ice precipitation is immediately south of the lake. Within a square with sides $\sim 65 \mathrm{~km}$ immediately south of the lake, the daily temperature cycle is regular, with little variability. Water vapor and cloud blanketing raises nighttime surface temperature by up to $18 \mathrm{~K}$ relative to the dry run, but the net increase in daytime surface temperature due to the lake is small or negative because of ice-particle scattering (Figure 3a). Despite ice-particle scattering, afternoon surface temperature exceeds $273 \mathrm{~K}$ in the area of peak water-ice precipitation, so snow falling onto bare ground during the afternoon will melt. Snow falling onto ground that is cooled due to the increased albedo of snow that has fallen during the night may or may not melt, depending on the grain size, thickness, and dust content of the nighttime snow layer [Clow, 1987].

[26] To track water and ice mass budgets, we average over a square $400 \mathrm{~km}$ on a side which contains the lake but is centered $100 \mathrm{~km}$ south of the lake in order to enclose the cloud. The time dependence of the water substance mass budget is dominated by a strong afternoon peak in atmospheric water vapor ( $\sim 2.5$ times the predawn minimum of $\sim 9 \mathrm{Mt})$ at a time when atmospheric temperatures are highest (Figure $3 b)$. The mass of water ice in the atmosphere is independent of time of day and averages $10 \mathrm{Mt}$ during sols 5-7. The majority of the water vapor injected into the system precipitates as water ice during the night (see section 4.4). Again, notice that atmospheric temperature does not exceed $273 \mathrm{~K}$, so liquid water aerosol is never stable.

\subsection{Structure of the Buoyant Plume}

[27] Latent heat release drives plume ascent. Figure 4 is a predawn snapshot: water ice mass ratio in the plume core 


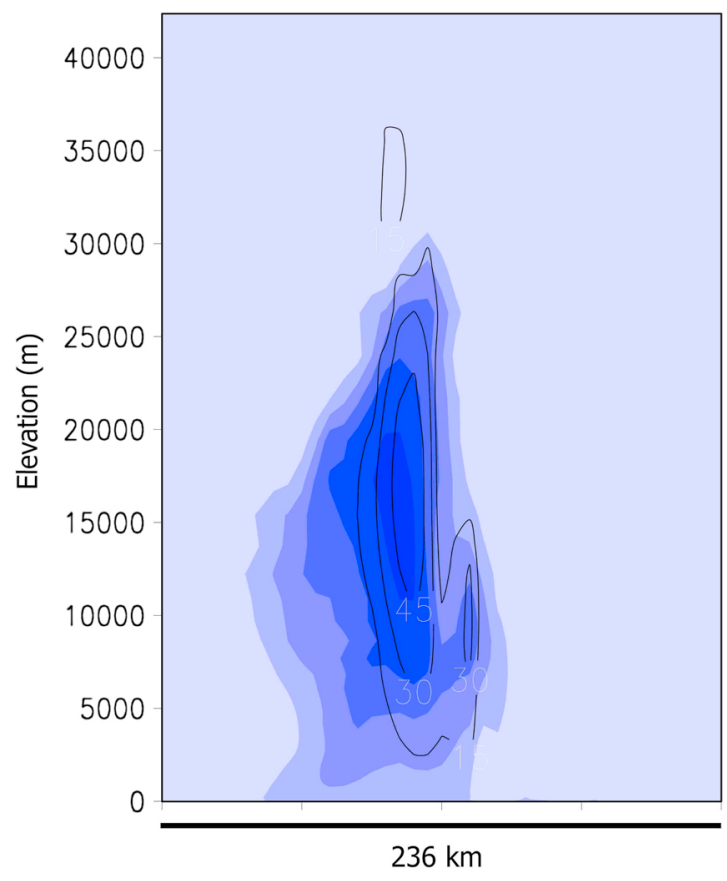

Figure 4. N-S cross section through lake storm. Blue tint corresponds to increasing water ice fraction (interval 0.002 , maximum value 0.011 ). Labeled contours correspond to bulk vertical velocity in $\mathrm{m} \mathrm{s}^{-1}$. The $y$ axis is vertical distance in $\mathrm{m}$, and the $x$ axis gives horizontal scale (40 simulation units $=$ $236 \mathrm{~km})$.

exceeds $1 \%$. At $17.5 \mathrm{~km}$ elevation, more than $95 \%$ of water substance is in the condensed phase and vertical velocities reach $54 \mathrm{~m} \mathrm{~s}^{-1}$. There is now little energy to be gained from further condensation, so the plume slows and broadens.
Sublimation, entrainment, and especially precipitation, all lower the ratio of ice to vapor. The plume overshoots its equilibrium level, peaking near $35 \mathrm{~km}$.

[28] At a given altitude, plume updraft velocities are strongest just before dawn and weakest in early afternoon. This diurnal cycle in plume behavior corresponds to three related changes in the state of the atmosphere just upwind of the lake. First, the Planetary Boundary Layer (PBL) pinches and swells during the diurnal cycle. The greater depth and intensity of turbulent mixing during the day leads to more entrainment of moist air by the ambient atmosphere, where it does not contribute to the plume. Higher air temperatures disfavor crystallization at low altitudes during the day. Together, these two changes allow more vapor to escape during the day, by advection downwind within the thickened PBL, and not contribute to the plume. Finally, during the day, the excess of lake temperature over land temperature is small, and convergence is weak, so the shear velocity $u *$ is small. Therefore, relatively little vapor mixes from the lake surface boundary layer into the atmosphere. During the night, the greater land-lake temperature contrast is associated with stronger convergence. More vapor is mixed above the surface layer and entrained by the plume. Allowing for dynamic lake surface roughness $\left(z_{0} \sim u_{*}^{2}\right)$ increases the sensitivity of plume velocity to time of day, which confirms the effect of surface layer dynamics on the diurnal cycle.

\subsection{Precipitation}

[29] Precipitation is strongly peaked just downwind of the lake. Figure 5a shows that time-averaged snowfall is everywhere $<0.006 \times$ its peak value at distances $>150 \mathrm{~km}$ from that spatial peak. Peak snowfall (Figure 5b) shows a similar, but more noisy, pattern, with peak precipitation $>4.5 \mathrm{~mm} \mathrm{~h}^{-1}$ only in a small area beneath the buoyant plume. Precipitation rates increase by a factor of 4 during the night, with a rapid a)

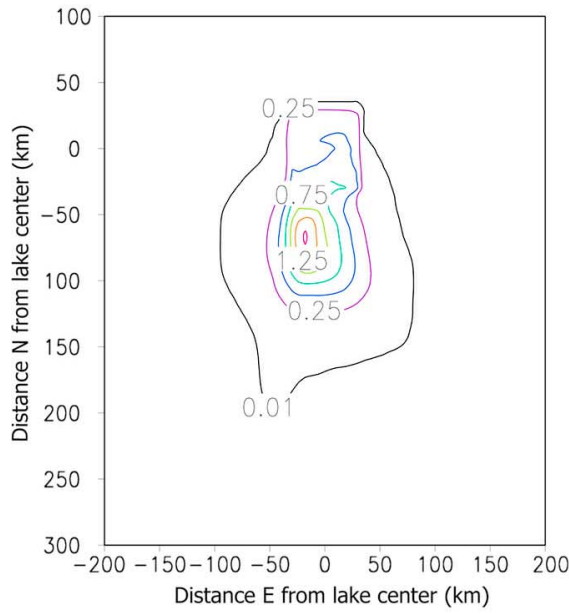

b)

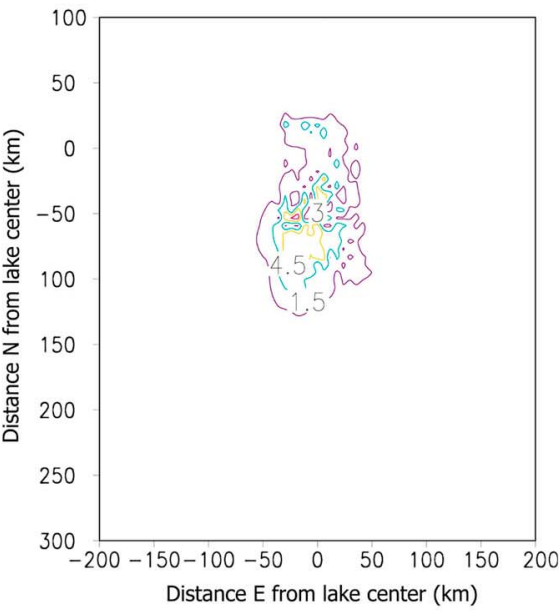

C)

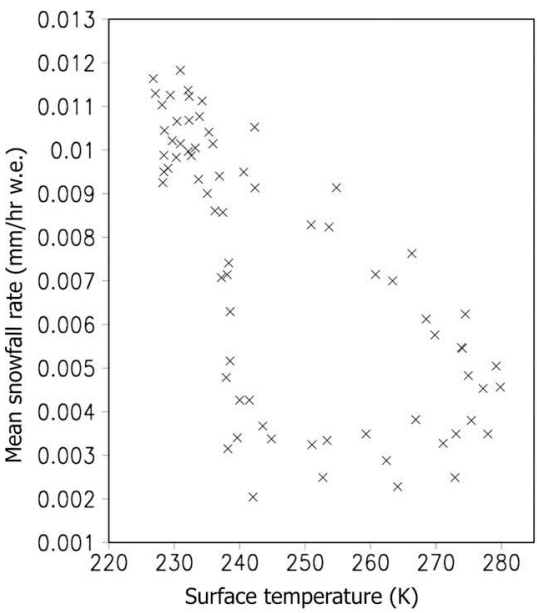

Figure 5. Precipitation (snowfall) from our REF simulation. (a) Mean precipitation $\left(\mathrm{mm} \mathrm{h}^{-1}\right.$ water equivalent) for reference simulation. Peak value is $1.5 \mathrm{~mm} \mathrm{~h}^{-1}$. (b) Maximum precipitation $\left(\mathrm{mm} \mathrm{h}^{-1}\right.$ water equivalent) for reference simulation. Peak value is $6 \mathrm{~mm} \mathrm{~h}^{-1}$. (c) Diurnal cycle in spatially averaged precipitation $\left(\mathrm{mm} \mathrm{h}^{-1}\right)$ as a function of average surface temperature $(\mathrm{K})$ : snow falls at a high rate during the night but is reduced following sunrise (diagonal branch), leveling out at values $\sim 1 / 3$ of the nighttime peak during the late afternoon (horizontal branch). Sunset permits a rapid return to high rates of snowfall (vertical branch). 


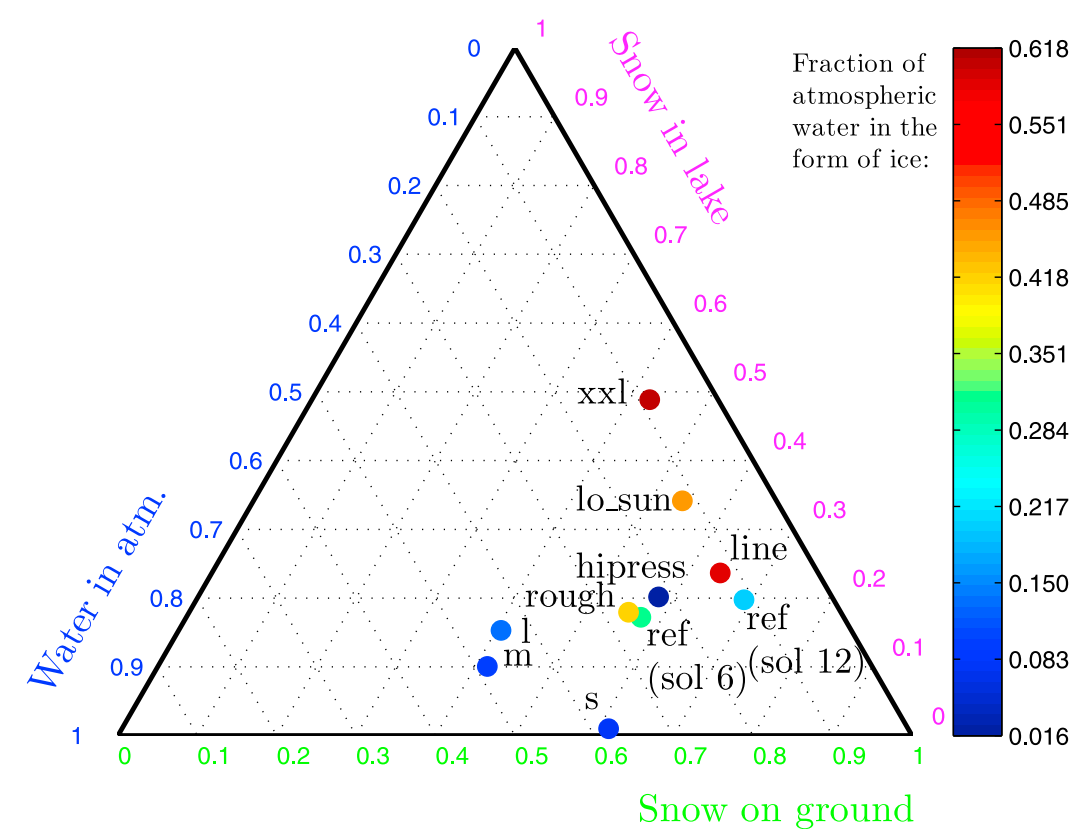

Figure 6. Fate of vapor released from the lake (precipitation efficiency). Colored dots correspond to a model's inventory of water substance after 6 sols, after subtracting the inventory of a lake-free run. Color corresponds to fraction of atmospheric water in the ice phase: red is more ice-rich, and blue is more vaporrich. Only snow on ground can contribute to localized geomorphology. Water substance in atmosphere can contribute to regional and global climate change: greenhouse warming is increasingly likely as the mass of atmospheric water increases.

decline during the morning to a lower, stable afternoon rate (Figure 5c).

[30] Diurnally averaged precipitation is steady in location over the 12 days of our extended REF simulation. The total precipitation rate increases slightly with time.

\subsection{Precipitation Efficiency}

[31] Figure 6 and Table 2 show the fate of released vapor at the end of sol 6 in REF. The majority of the vapor precipitates $<200 \mathrm{~km}$ from the lake. Of the vapor that reaches distances $>200 \mathrm{~km}$ from the lake, the majority is in the form of vapor at the end of the simulation.

[32] After 6 days of the REF run, the outermost (hemispheric) grid contains $\sim 300 \mathrm{Mt}$ more atmospheric water than the DRY run (please refer to Table 1 for details of runs and parameters). This is equivalent to a global surface liquid water layer $2 \mu \mathrm{m}$ thick, or a lake depth of $7 \mathrm{~cm}$. This is radiatively unimportant on the global scale and less than the current global average ( $\sim 17 \mathrm{pr} \mu \mathrm{m}$ in the northern hemisphere, $\sim 9.5 \mathrm{pr} \mu \mathrm{m}$ in the south [Smith, 2002]). The added vapor will presumably precipitate as ice on the winter pole, which is outside the space and time limits of our simulation. If all vapor precipitates in a single season on a polar cap of area $10^{6} \mathrm{~km}^{2}$, it would form a layer $0.3 \mathrm{~m}$ thick. Layers of this thickness could be resolved by the HiRISE camera on a gently sloping exposure.

[33] Figure 6 understates the fraction of water that precipitates locally if the conditions that maintain a liquid surface are maintained indefinitely. This is because some of the water

Table 2. Vapor Fate ${ }^{\mathrm{a}}$

\begin{tabular}{|c|c|c|c|c|c|c|}
\hline Run & $\begin{array}{l}\text { Evaporation Rate } \\
\qquad\left(\mathrm{mm} \mathrm{h}^{-1}\right)\end{array}$ & $\begin{array}{c}\text { Water in } \\
\text { Atmosphere }\end{array}$ & $\begin{array}{c}\text { Total Atmosphere } \\
(\%)\end{array}$ & $\begin{array}{l}\text { Snow } \\
\text { in Lake }\end{array}$ & $\begin{array}{c}\text { Snow Beyond } \\
\text { Lake }\end{array}$ & $\begin{array}{c}\text { Total Snow } \\
(\%)\end{array}$ \\
\hline $\mathrm{DRY}^{\mathrm{b}}$ & 0 & 420 & 100 & 0 & 0 & 0 \\
\hline REF (sol 6) & 2.5 & 334 & 26 & 234 & 741 & 74 \\
\hline REF (sol 12) & 2.5 & 316 & 11 & 543 & 1942 & 89 \\
\hline LINE & 3.7 & 1420 & 12 & 2701 & 7355 & 88 \\
\hline $\mathrm{S}$ & 16.2 & 26 & 38 & 0.8 & 42.7 & 62 \\
\hline M & 3.6 & 68 & 49 & 12 & 59.1 & 51 \\
\hline $\mathrm{L}$ & 2.5 & 228 & 44 & 84 & 204 & 56 \\
\hline XXL & 2.9 & 899 & 9 & 5030 & 4503 & 91 \\
\hline ROUGH & 2.6 & 381 & 27 & 250 & 793 & 73 \\
\hline LO_SUN & 2.8 & 176 & 12 & 484 & 820 & 88 \\
\hline HIPRESS & 3.4 & 175 & 22 & 484 & 820 & 78 \\
\hline
\end{tabular}

${ }^{\mathrm{a}}$ End of sol 6 . Units are Mt (10 $0^{6}$ metric tons). See also Figure 6.

${ }^{b} \mathrm{RUN}$ is subtracted from all other runs. 


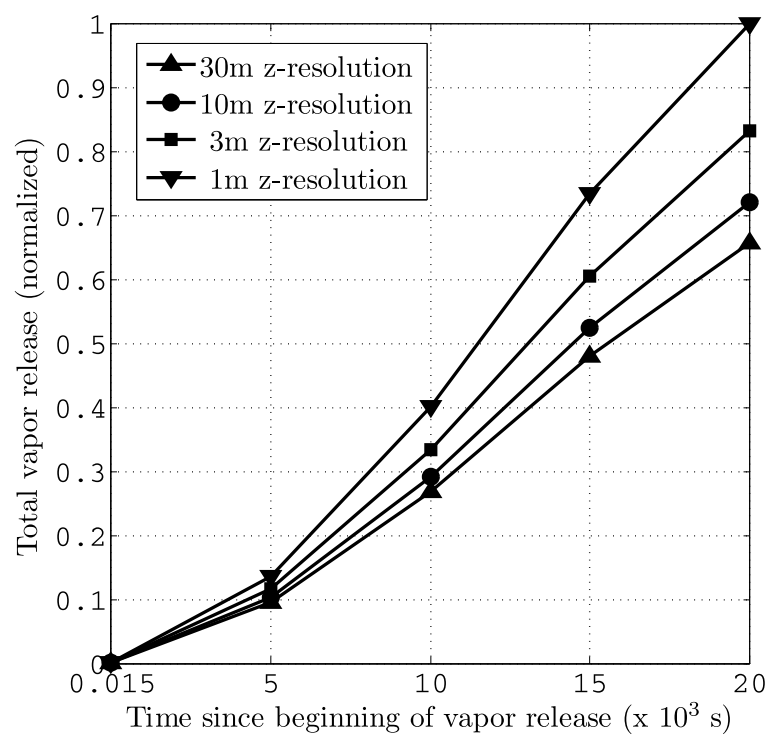

Figure 7. Outcome of vertical resolution sensitivity test. Values are normalized to total vapor release at the end of the $1 \mathrm{~m}$ resolution run.

that is in the atmosphere at the end of sol 6 will precipitate locally. In an extended run (ref (sol 12) in Figure 6), the fraction of water that precipitates locally is increased.

\section{Sensitivity Tests}

\subsection{Vertical Resolution}

[34] We carried out a sensitivity test to determine model vapor release as a function of vertical resolution. The computational expense of increasing vertical resolution scales as $N \log (N)$, so runs were for only $\frac{1}{4}$ sol starting at $\sim 12$ noon Local Solar Time. Vapor release rate is moderately sensitive to model vertical resolution. Increasing surface layer thickness by a factor of 30 decreases vapor release by $35 \%$ (Figure 7). Therefore, our modeled afternoon vapor release (and precipitation) rates are probably underestimates. (In an earlier report (Kite et al. [2010]), we stated the results of a sensitivity test carried out at night, for which the sensitivity has similar magnitude but opposite sign.)

\subsection{Horizontal Resolution}

[35] We carried out a simulation, HIRES, that added an inner grid with $2.0 \mathrm{~km}$ horizontal resolution. (HIRES was initialized from REF output after 2 days). Overall storm structure was similar, although secondary plumes developed in addition to the main plume. Peak vertical velocity increased by $34 \%$, peak time-averaged vertical velocity by $57 \%$, and cloud height by $12 \%$, relative to REF. When averaged to the lower resolution of REF, these differences decreased to $16 \%, 26 \%$, and $12 \%$, respectively (Figure 8 ). Although these differences are not negligible, we observed that our main results (strong plume and localized precipitation) were not affected by the increase in horizontal resolution. Simulations which use resolutions intermediate between eddy resolving and the mesoscale are known to suffer from artifacts caused by aliasing of barely resolved eddies by the grid cell size, and we observed $2 \Delta x$ noise in HIRES. For these reasons, and because of the computational expense of high resolution, we held model horizontal resolution at $5.9 \mathrm{~km}$ for the remainder of our sensitivity tests.

\subsection{Size of Idealized Lake}

[36] Small lakes in our simulations are unable to drive deep convection, and have weaker localized precipitation. We modeled square lakes with areas of $\sim 35 \mathrm{~km}^{2}(\mathrm{~S})$, $\sim 300 \mathrm{~km}^{2}(\mathrm{M}), \sim 1700 \mathrm{~km}^{2}$ (L), and $\sim 29000 \mathrm{~km}^{2}$ (XXL), in addition to the $\sim 4000 \mathrm{~km}^{2}$ REF simulation.

[37] Deep moist convection was not observed in the S and $\mathrm{M}$ simulations. To verify that this was not an artifact of insufficient model resolution, we ran a $2 \mathrm{~km}$ resolution nested grid on M. Although peak vertical velocities did increase in the nested grid relative to the default resolution model, lake source vapor did not reach altitudes much greater than the planetary boundary layer and, as in the default resolution model, was passively advected downwind. Given our particular choice of atmospheric boundary conditions (presentday orbital conditions, low latitude, and southern summer), lake size $>10^{3} \mathrm{~km}^{2}$ is required for deep moist convection. If vapor is funneled to a single central plume of constant radius and entirely condensed, we would expect plume vertical velocity to scale linearly with lake area. Figure 9 shows that this expectation is borne out for lakes of size $10^{2.5} \mathrm{~km}^{2}$ to $10^{3.5} \mathrm{~km}^{2}$, but overestimates lake storm convective intensity for the largest simulation. This XXL simulation is unusual because it has a much broader area of strong upwelling than the smaller lakes, which explains why its convective velocities are not as high as expected. In the smallest lake modeled, the lake-associated updrafts are so weak that they were difficult to separate from everyday planetary boundary layer convection.

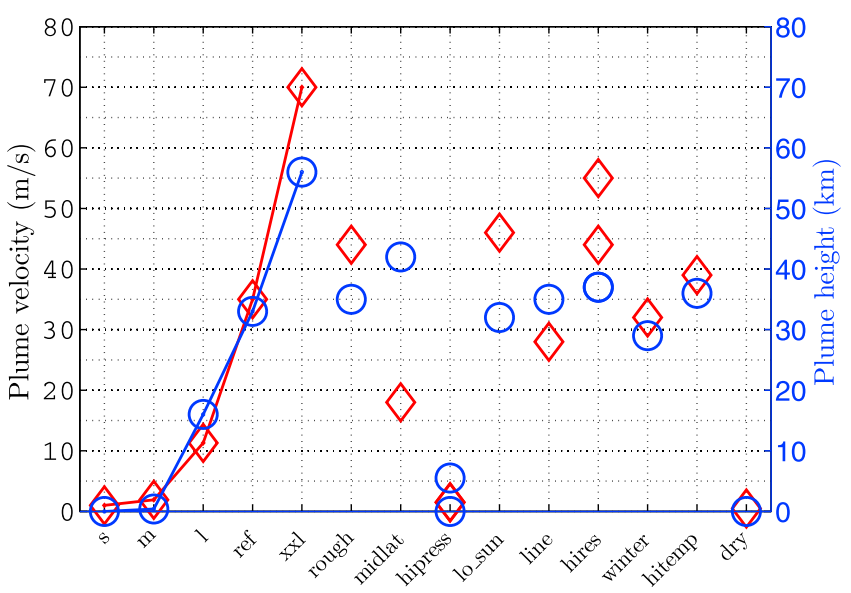

Figure 8. Intensity of moist convection for runs listed in Table 1. Red diamonds correspond to peak time-averaged plume velocity; blue circles correspond to plume height. Lines connect the sequence of 5 simulations in which only size was varied. Plume height is defined as the altitude at which the plumes' spatial peak in time-averaged ice mixing ratio falls below $10^{-3}$. The two blue circles for HIPRESS correspond to ice mixing ratios of $10^{-3}$ (lower circle) and $10^{-4}$ (upper circle). The two red diamonds for HIRES correspond to peak velocities at $2 \mathrm{~km}$ resolution (upper diamond) and peak velocities smoothed to $5.9 \mathrm{~km}$ resolution (lower diamond). 


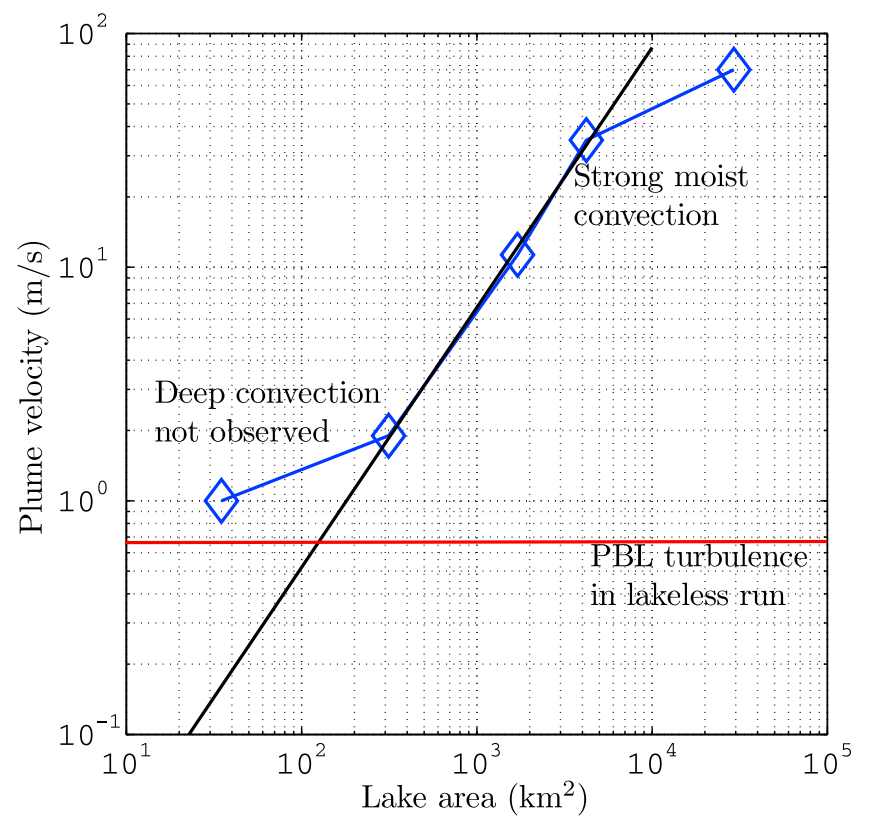

Figure 9. Dependence of plume convective intensity on lake size. The black line is a best fit power law (slope of 1.11) to the three central points. It intersects the lakeless run planetary boundary layer (PBL) turbulence at a lake size of $\mathrm{O}\left(10^{2}\right) \mathrm{km}^{2}$; below this lake size, we would not expect to recognize a plume. Explanations of the similarity of the power law exponent to 1, and the deviation of the largest lake from this slope, are provided in the text.

[38] Because lake-induced convergence (Figure 2d) efficiently funnels lake-released vapor into one buoyant plume, plume velocity and plume height increase with lake size (Figure 8). Greater plume heights promote ice formation, and the ice fraction of atmospheric water increases with lake size (colors in Figure 6). This is a self-sustaining feedback, because ice formation provides energy for plume ascent, which in turn creates low pressure above the lake and drives convergence.

[39] Larger lakes inject proportionately less water into the global atmosphere. More than $1 / 3$ of the water released in the $\mathrm{S}, \mathrm{M}$ and $\mathrm{L}$ simulations is in the atmosphere at the end of the simulation; $<14 \%$ is in the form of ice. In the XXL simulation, the fraction of released water that is precipitated locally is $>90 \%$, and most of the atmospheric water is ice aerosol that would probably precipitate locally if the lake surface froze over. The LINE source has a similar lake area to the square XXL run, and behaves similarly in having a small atmospheric water fraction and a large ice aerosol fraction. This suggests that this trend of increased localized precipitation fraction with increased lake area does not depend on lake geometry.

\subsection{Surface Roughness Parameterization}

[40] Our default run assumes fixed lake surface roughness, but water surface roughness increases with wind speed. A more realistic approximation is that of Garrett [1992] as given by equation 7.21 of Pielke [2002]:

$$
z_{0}=1 \times 10^{-4}+\left(0.01625 u_{*}^{2} / g\right)
$$

where we have added the first term to maintain numerical stability. This remains an adequate fit to the much larger data sets now available [Zeng et al., 1998]. The time-averaged lake roughness with this parameterization is $0.0126 \mathrm{~m}$, and is a factor of three higher during the night when near-surface winds are stronger.

[41] Our time-averaged results are insensitive to this more accurate lake surface roughness parameterization (Table 2 and Figure 6), although the very strong plumes seen during the night (when vapor injection rate is highest) increase both plume height and updraft velocity (Figure 8).

\subsection{Line Source}

[42] Our line source is intended to sketch an outflow channel during a channel-forming flood. It is a N-S oriented, straight trough of depth $1.5 \mathrm{~km}$, floor width $30 \mathrm{~km}$, wall slope 0.13 , and length $880 \mathrm{~km}$. The floor is flooded. Of the resulting snow, $23 \%$ falls back into the lake and a further $70 \%$ falls within $100 \mathrm{~km}$ of the edge of the trough. The diurnal cycle consists of a strong, steady, spatially continuous line storm on the west edge of the trough during the night, and a clumpy, broken line of weak updrafts some distance east of the trough during the day. Time-averaged vertical velocity and precipitation fields do not show this clumpiness: instead, there is a trend of monotonically increasing vertical velocity and precipitation rates toward the north, because the background wind field advects the upper parts of the cloud toward the north.

[43] We do not consider the influence of the flowing water on surface roughness, nor the drag of the flowing water on the atmosphere.

\subsection{Season}

[44] In southern winter (also aphelion season) the sign of the Hadley circulation reverses. In a run at $\mathrm{Ls}=90^{\circ}$, the GCM boundary conditions produced ESE directed time-averaged winds at altitudes below $\sim 15 \mathrm{~km}$, and SW directed timeaveraged winds at higher altitudes. The highest snowfall rates were just ESE of the lake, reflecting steering of the plume by regional winds. Total localized precipitation was the same as in REF to within $7 \%$.

\subsection{Latitude}

[45] A cyclonic circulation does not develop in our REF run. To determine if Coriolis effects can produce a cyclone at higher latitudes, we ran a test at $45^{\circ} \mathrm{S}$ latitude. As expected given the small size of the lake, the lake-driven circulation is too weak to restructure the background wind field and a lake-induced standing cyclone does not form.

[46] The total localized precipitation in the midlatitude run is only $1 / 3$ of the total localized precipitation in the equatorial runs. Since vapor release is similar, vapor is being converted to localized precipitation with a smaller efficiency. Peak time-averaged column ice fractions are $<40 \%$ in the midlatitude run, compared to $>70 \%$ in the reference run (Figure 2e). This is because both runs are close to southern summer solstice. The southern midlatitude site is in sunlight for $2 / 3$ of each day, and has air temperatures higher by $20 \mathrm{~K}$ on average than the equatorial site. Because of the lower supersaturations, water in the midlatitude plume must be lifted $5 \mathrm{~km}$ higher to obtain a given ice fraction than in the 
equatorial plume. Therefore, more vapor escapes to the regional atmosphere.

\subsection{Faint Young Sun}

[47] Many channel networks on Mars formed when the Sun was fainter. The solar luminosity $L$ at the HesperianAmazonian boundary was $0.78-0.85 \times$ present-day solar luminosity $L_{0}$, and $L$ at the Noachian-Hesperian boundary was 0.75-0.77 $\times L_{0}$ [Bahcall et al., 2001; Hartmann, 2005]. The uncertainty is due to differences among the models that map crater density onto absolute age: the solar evolution model has much smaller error bars. The Juventae plateau channel networks (paper 2) could be as old as Hesperian [Le Deit et al., 2010], so we ran a test at $0.75 L_{0}$. As well as being less luminous, the young Sun was also $1.5 \%$ cooler [Bahcall et al., 2001]. We ignore the resulting small shift in the solar spectrum and simply reduce the flux at all wavelengths by $25 \%$.

[48] Colder air temperatures under the faint young sun lower the cloud base by $\sim 5 \mathrm{~km}$. Peak updraft velocities are $>50 \mathrm{~m} \mathrm{~s}^{-1}$ in both simulations, but occur at lower elevations in the faint young sun simulation. Because supersaturations are higher at all colder altitudes, ice growth is favored and the fraction of atmospheric water that is ice increases from $32 \%$ in REF to $47 \%$ in LO SUN.

[49] We conclude that localized precipitation is favored by reduced solar luminosity. However, this is not true for melting (section 6).

\subsection{Paleoatmospheric Pressure}

[50] Figure 1 suggests that localized precipitation will not occur if atmospheric pressure is greatly increased. To test this, we increased pressure to 10x Present Atmospheric Level (PAL) on all the mesoscale grids (run HIPRESS). Deep moist convection is suppressed, uplift velocities are reduced, and comparatively little vapor reaches cloud-forming altitudes. No lake source ice is found above $10 \mathrm{~km}$, and little ice aerosol forms $(1.6 \%$ of atmospheric water mass on the inmost grid, versus $32 \%$ in REF). Precipitation is reduced by $20 \%$, and preliminary runs at 20x PAL lead us to expect that further increases in pressure will further reduce localized precipitation.

\section{A Probabilistic Model of Snowpack Melting on Ancient Mars}

[51] Localized precipitation is not occurring today, so our model can only be tested against the geologic record of past events. Geology records erosion and sediment transport, which require melting. If storm systems in a cold background climate deliver snow locally, and that snow sublimes away without melting, it will leave no geological trace. Therefore, a melting model is required to test the localized precipitation hypothesis. For a lake lifetime of 1 Earth year (similar to expected chaos outflow durations [Andrews-Hanna and Phillips, 2007; Harrison and Grimm, 2008]) and assuming that seasonal effects on the storm are minor, $\sim 2 \mathrm{~m}$ of snow is predicted to accumulate downwind of the lake by our reference simulation, assuming a snowpack density of $350 \mathrm{~kg} \mathrm{~m}^{-3}$. Will it melt?

[52] We expect the lifetime of snowpack against sublimation and wind erosion to be $\geq O(1)$ year, so that the annual maximum temperature is that which is relevant for snow melting. For predicted snowpack depths $O(1) \mathrm{m}$, this residence time is supported by GCM simulations [e.g., Madeleine et al., 2009, Table 1]. A simple energy argument gives the same result:

$$
t_{\mathrm{s}} \sim \frac{d_{\text {snow }} \rho_{\text {snow }} L_{\mathrm{s}}}{F_{\text {Sun }} \eta f_{d}}
$$

which, with snow depth $d_{\text {snow }}=1 \mathrm{~m}$, snow density $\rho_{\text {snow }}=$ $350 \mathrm{~kg} \mathrm{~m}^{-3}$, solar flux $F_{\text {Sun }}=300 \mathrm{~W} \mathrm{~m}^{-2}$, fraction of solar energy used for sublimation $\eta=0.1$, day fraction $f_{d}=0.5$, gives sublimation time $t_{\mathrm{s}}=1.0$ Mars year. With surface pressures on the plateau of $\approx 1000 \mathrm{~Pa}$, maximum modeled surface shear stress is not sufficient to initiate motion of snow that is resting on the ground [Greeley and Iverson, 1989].

[53] In general, melting probability will depend on orbital elements including obliquity and precession, latitude, age (via solar luminosity), material properties, and the lifetime of snowpack against sublimation losses to planetary cold traps. For age $\geq 20 \mathrm{Ma}$, deterministic chaos makes orbital elements unreliable: as our interest is in ancient Mars our model is therefore probabilistic. We model temperatures at the equator, because $64 \%$ of the sedimentary rocks on Mars are within $10^{\circ}$ of the equator [Malin et al., 2010, Figure16.txt in their online supporting data], and our modeling target in paper 2 is at $5^{\circ} \mathrm{S}$.

\subsection{A Simple Energy Balance}

[54] The energy balance of a snow-bearing surface on Mars is [Dundas and Byrne, 2010]

$$
\frac{\partial U}{\partial t}=(1-\alpha) \mathrm{SW} \downarrow+\epsilon \mathrm{LW} \downarrow-\epsilon \sigma T^{4}-\mathrm{SH}-C_{\mathrm{n}}-L_{\mathrm{s}} \frac{\partial m_{w}}{\partial t}
$$

where the left-hand side is gain of energy by the surface layer, $\alpha$ is surface albedo, $\mathrm{SW} \downarrow$ is sunlight reaching the surface, $\epsilon \approx$ 0.98 for ice is thermal emissivity, LW $\downarrow$ is the greenhouse effect, $\sigma$ is the Stefan-Boltzmann constant, $T$ is surface temperature, $\mathrm{SH}$ is net sensible heat flux from the surface to the atmosphere, $C_{\mathrm{n}}$ is net conductive heat flux from the surface into the ground, $L_{s}$ is the latent heat of sublimation of water, and $\partial m_{w} / \partial t$ is the sublimation rate.

[55] The minimum sublimation rate (in the absence of wind) is given by [Hecht, 2002; Dundas and Byrne, 2010]

$$
\frac{\partial m_{w}}{\partial t}=0.14 \Delta \eta \rho_{\text {asl }} D\left(\left(\frac{\Delta \rho_{\text {asl }}}{\rho_{\text {asl }}}\right)\left(\frac{g}{\nu_{\mathrm{a}}^{2}}\right)\left(\frac{\nu_{\mathrm{a}}}{D_{\mathrm{a}}}\right)\right)^{1 / 3}
$$

where $\Delta \eta$ is the difference between atmospheric and surface gas water mass fractions, $\rho_{\text {asl }}$ is the atmospheric density within the surface layer, $D_{\mathrm{a}}$ is atmospheric mass diffusivity, $\Delta \rho_{\text {asl }} / \rho_{\text {asl }}$ is the normalized density difference between the moist near-surface atmosphere and ambient atmosphere, and $\nu_{\mathrm{a}}$ is kinematic viscosity. We parameterize the temperature dependency of $\nu_{\mathrm{a}}$ and $D_{\mathrm{a}}$ following Dundas and Byrne [2010].

[56] Melting is possible if $\partial U / \partial t \geq 0$ at $T=273.15 \mathrm{~K}$. We set up optimistic conditions for melting, and ask: with what probability do orbital conditions permit melting?

[57] Evaporative cooling is handled following Dundas and Byrne [2010]: we obtain $165 \mathrm{~W}$ assuming $70 \%$ humidity, 


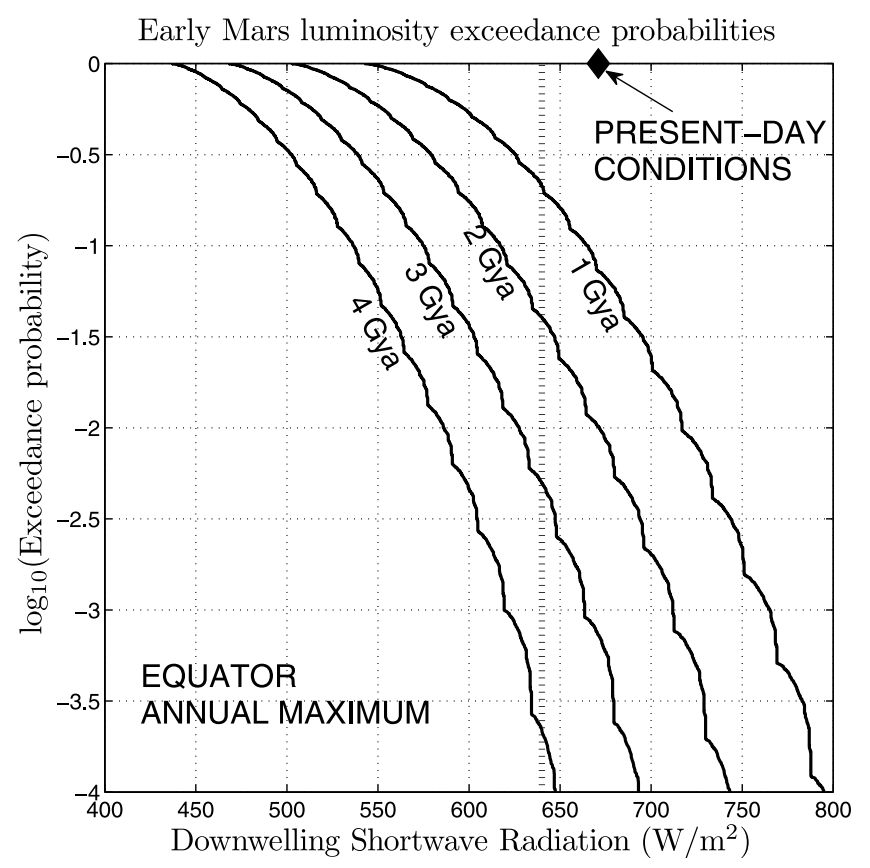

Figure 10. Exceedance probabilities for annual maximum sunlight at Mars' equator. Vertical dashed line is $640 \mathrm{~W} \mathrm{~m}^{-2}$, the minimum for melting (see text). The small wiggles in the solid curves are interpolation artifacts. Snow instantaneously emplaced at Mars' equator with the current orbital conditions and solar luminosity would melt. For progressively earlier times (reduced solar luminosity), the probability of melting decreases. Gya, gigayears ago.

atmospheric pressure $1220 \mathrm{~Pa}$, and zero wind. The more sophisticated surface layer theory of Clow and Haberle [1990] gives an evaporative cooling rate $>2$ times less than found by Dundas and Byrne [2010] (and $>4$ times less than that found by Ingersoll [1970]) for roughnesses $z_{0}<0.3 \mathrm{~mm}$ that are appropriate for polar snow [Brock et al., 2006]. Therefore, our parameterization may overestimate evaporative cooling by free convection. We assume still conditions, so that cooling by wind-driven turbulent fluxes (forced convection) is negligible: this assumption is favorable for melting. We also neglect the turbulent flux of sensible heat $\mathrm{SH}$, which is a factor of $>10$ smaller than evaporative cooling for these conditions [Hecht, 2002]. The noontime conductive heat flow $C_{\mathrm{n}}$ can be parameterized assuming the temperature falls to the diurnal average temperature at a depth equal to twice the diurnal skin depth. Assuming a diurnal average temperature during the hottest season of $220 \mathrm{~K}$, this gives

$$
C_{\mathrm{n}}=k \frac{\partial T}{\partial z}=k \frac{273.15-220}{2 \sqrt{\kappa P / \pi}}
$$

For thermal conductivity $k=0.125 \mathrm{~W} \mathrm{~m}^{-1} \mathrm{~K}^{-1}$ for snow [Carr and Head, 2003], sol length $P=88775.204$ s, and thermal diffusivity $\kappa=2.04 \times 10^{-7} \mathrm{~m}^{2} \mathrm{~s}^{-1}$ appropriate for low-density snow, we obtain $C_{\mathrm{n}}=40.3 \mathrm{~W} \mathrm{~m}^{-2}$.

[58] The greenhouse effect LW $\downarrow$ at the time of peak surface temperature is assumed to be $55 \mathrm{~W} \mathrm{~m}^{-2}$ (European Mars Climate Database). We do not consider the additional greenhouse forcing from the lake storm nor from a possible past stronger greenhouse effect. For dusty snowpack with albedo 0.28 , the resulting minimum on SW is $640 \mathrm{~W} \mathrm{~m}^{-2}$.

[59] We calculate the maximum equatorial luminosity for all ages, seasons, and orbital conditions. The age-dependent solar luminosity is taken from the standard solar model of Bahcall et al. [2001]. We then weight the annual maximum luminosity results by the age-dependent probability densities for obliquity and eccentricity from Laskar et al. [2004], assuming that obliquity and eccentricity are not strongly correlated. (In the 0.25 Gyr solutions provided by J. Laskar at http://www.imcce.fr/Equipes/ASD/insola/mars/mars.html, obliquity and eccentricity are not strongly correlated.) A value of $640 \mathrm{~W}$ is exceeded with $21 \%$ probability at $1 \mathrm{Ga}$, but with only $0.5 \%$ probability $3 \mathrm{Ga}$ (Figure 10 ).

\subsection{A 1-D Column Model}

[60] Next we calculate temperatures within snowpack for the full range of obliquities $\left(\phi, 0^{\circ} \rightarrow 80^{\circ}\right)$, eccentricity $(e, 0.0 \rightarrow 0.175)$, longitudes of perihelion $\left(L_{p}\right)$ and solar longitudes that are sampled by Mars [Laskar et al., 2004]. We use a $1 \mathrm{D}$ thermal model to calculate temperature $T$ within snowpack at a range of seasons, ignoring the greenhouse effect $\mathrm{LW} \downarrow . T$ is solved for by matrix inversion for the linear (conduction) part and iteratively for the nonlinear contribution of radiation and evaporative cooling in the topmost layer. The time step is $12 \mathrm{~s}$. Evaporative cooling is handled following Dundas and Byrne [2010] with optimistic assumptions as in the simple energy balance. Each run is initialized with surface temperature $T_{\mathrm{s}}$ at instantaneous thermal equilibrium with incoming sunlight, decaying with an $e$-folding depth equal to the diurnal skin depth $d=\sqrt{(k \rho) /\left(P c_{\mathrm{p}} \pi\right)}$ to an energy-weighted time-averaged equilibrium temperature at depth. (Here, $k$ is thermal conductivity, $\rho$ density, $P$ the length of 1 sol in seconds, and $c_{p}$ specific heat capacity of the subsurface.) We then integrate forward in time for multiple sols, but with seasonal forcing held constant, until sol peak $T_{\mathrm{s}}$ has converged. Models that neglect the greenhouse effect provide a good approximation to Mars' observed surface temperature.

[61] Atmospheric contributions $\mathrm{LW} \downarrow$ are parameterized as a time-independent greenhouse temperature increase, $\Delta T_{\mathrm{a}}$. The purpose of adding the atmospheric contribution in postprocessing is to allow different models of the past atmosphere to be compared to each other without rerunning the ensemble of $\sim 10^{5}$ column models. Typical present-day values are $\Delta T_{\mathrm{a}}=5-10 \mathrm{~K}$ [Read and Lewis, 2004]. This averages over strong nighttime warming, which is irrelevant for melting, and weak afternoon warming, which is critical to melting. Setting $\Delta T_{\mathrm{a}}$ to the time average of presentday greenhouse warming will therefore lead to an overestimate of melting. Instead, we want to know the value $\Delta T_{\text {a }}$ at the peak temperatures relevant to melting. We make the approximation

$$
\Delta T_{\mathrm{a}} \simeq T_{\mathrm{s}, \text { max }}-\sqrt[4]{\sigma T_{\mathrm{s}, \text { max }}^{4}-\frac{\mathrm{LW} \downarrow \epsilon}{\sigma}}
$$

The Mars Climate Database Mars Year 24 simulation shows $\Delta T_{\mathrm{a}} 5-7 \mathrm{~K}$ at low latitudes. This excludes the dust storm 
Early Mars snowpack temperature exceedance probabilities

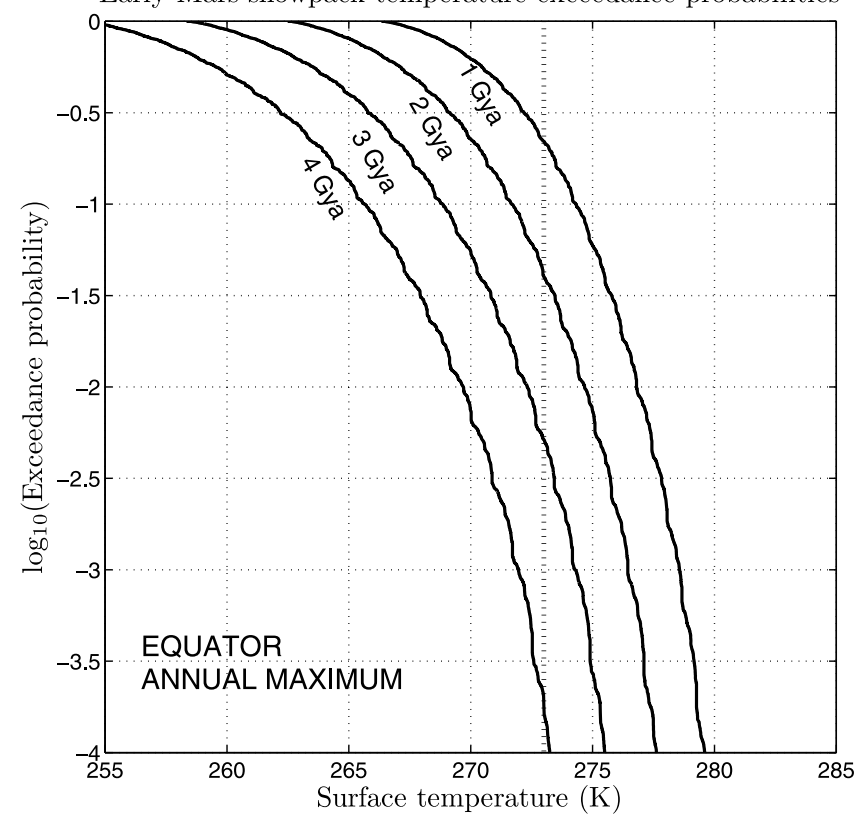

Figure 11. Exceedance probabilities for annual peak temperature of snowpack at Mars' equator from our 1-D column model. A dust-like albedo (0.28) is assumed. Vertical dashed line corresponds to the melting point. The small wiggles in the solid curves are interpolation artifacts. For progressively earlier times (reduced solar luminosity), the probability of melting decreases.

season, for which the neglect of atmospheric scattering leads to an overestimate of the net atmospheric contribution. We therefore adopt $6 \mathrm{~K}$ as our greenhouse forcing. Additional greenhouse forcing due to doubled $\mathrm{CO}_{2}$ is small and safely neglected [Wordsworth et al., 2010].

[62] Material properties for snowpack are again taken from Carr and Head [2003]: we assume a snowpack density of $350 \mathrm{~kg} \mathrm{~m}^{-3}$, thermal conductivity of $0.125 \mathrm{~W} \mathrm{~m}^{-1} \mathrm{~K}^{-1}$, and specific heat capacity $c_{p}$ of $1751 \mathrm{~J} \mathrm{~kg}^{-1}$, and neglect the temperature dependence of $k$ and $c_{p}$. We consider dirty $\mathrm{H}_{2} \mathrm{O}$ snow albedos between 0.28 and 0.4 . The smaller value is the present-day albedo of Mars' dust continents [Mellon et al., 2000], and the larger value is the upper end of the envelope that best fits the observed seasonal dependence of ephemeral equatorial snow on present-day Mars [Vincendon et al., 2010]. (Paper 2 provides a more detailed discussion of snowpack albedo.)

[63] Maximum temperature results are interpolated onto a finer mesh in orbital parameters $\left(\phi, e, L_{p}\right)$. We again weight the results using the probability distributions of Laskar et al. [2004]. Results for albedo 0.28 and latitude $0^{\circ}$ are shown in Figure 11. Temperatures greater than $273.15 \mathrm{~K}$ are not realistic, because snowpack temperature will be buffered by the latent heat of melting. The agreement between the melting probabilities obtained from the 1-D column model and the melting probabilities obtained from the simple energy balance argument is excellent (Figures 10 and 11). Even with the weak, present-day greenhouse effect, temperatures high enough for melting occur during $4 \%$ of the years $(0.1 \%$ for albedo 0.35 ). With an additional $6 \mathrm{~K}$ of greenhouse warming, melting occurs during $56 \%$ of years $(12 \%$ for albedo 0.35$)$.

\subsection{Discussion of Melt Model}

[64] The exact melting probabilities are unlikely to be correct, but we draw three lessons from these simple models:

[65] 1 . The probability of low-latitude melting is certainly higher for instantaneous emplacement of snow than for gradual (e.g., orbital equilibrium) emplacement of snow, and probably much higher. That is because gradual emplacement of annually persistent snow at the equator is only possible at high obliquity ( $50 \%$ of the time), while instantaneous emplacement can occur at any time. In addition, gradually emplaced snow will accumulate preferentially in areas where it is most stable: for example, shadowed areas, adverse steep slopes, and especially chasma and crater interiors where shadowing reduces peak temperature. Craters at $10^{\circ} \mathrm{S}$ in Sinus Sabeus appear to contain mantled, atmospherically emplaced ice deposits, providing direct evidence that equatorial ice on Mars does preferentially accumulate in crater interior cold traps [Shean, 2010]. The most compelling evidence for low-latitude glaciation on Mars is on the flanks of the Tharsis Montes, which have the lowest atmospheric pressures on the planet [Forget et al., 2006]. Liquid water exposed on the Tharsis Montes today would boil internally, leading to very rapid evaporative losses. Taken together, these observations suggest that localized precipitation is much more likely to melt than orbital equilibrium precipitation.

[66] Today's orbital conditions would lead to melting of snowpack on the equator (diamond in Figure 10). However, on today's Mars, snow is almost entirely restricted to high latitudes. Snow and ice on Mars do not melt in general because the area of transient liquid water stability changes on slow, orbital timescales $O\left(10^{4-5}\right)$ years. This allows time for ice to be removed (vertically or latitudinally) from the advancing zone of increased saturation vapor pressures, toward cold traps where melting cannot occur. Therefore the areas of surface ice and of transient liquid water stability rarely intersect. Theory, experiments, and the lack of geomorphic evidence for transient liquid water at the Phoenix landing site confirm this [Schorghofer, 2010; Hudson et al., 2007; Mellon et al., 2009]. Steep $\left(>20^{\circ}\right)$ gullied slopes within midlatitude and high-latitude craters are an exception [Morgan et al., 2010], assuming that the gullies formed from liquid water flows. In contrast, localized precipitation delivers snow on timescales $O\left(10^{-1}\right)$ year to a location uncorrelated with transient liquid water stability, so a wider range of orbital conditions will then allow melting.

[67] In the case of impact-induced precipitation, snow falling on hot ejecta will melt regardless of orbital conditions.

[68] 2. Because of the wide range of possible orbital states, the probability of melting is not zero, but neither is it large. The distribution of melting events $\left(T_{\mathrm{s}} \geq 273 . \mathrm{K}\right)$ with orbital parameters is shown in Figure 12. Relative to the probability density function (pdf) of obliquity, melting events are more probable at low obliquity than high; they are much more probable when perihelion occurs at equinox than when perihelion occurs at solstice; and they occur exclusively at moderate-to-high eccentricity. These results may be understood as follows. Moderate eccentricity is needed to offset the reduced solar luminosity. For example, at $3.0 \mathrm{Ga}$ and $e=0.11$, perihelion insolation is equivalent to insolation on a circular orbit today. Perihelion near equinox is needed to align the season when the noontime sun is highest at the equator with 

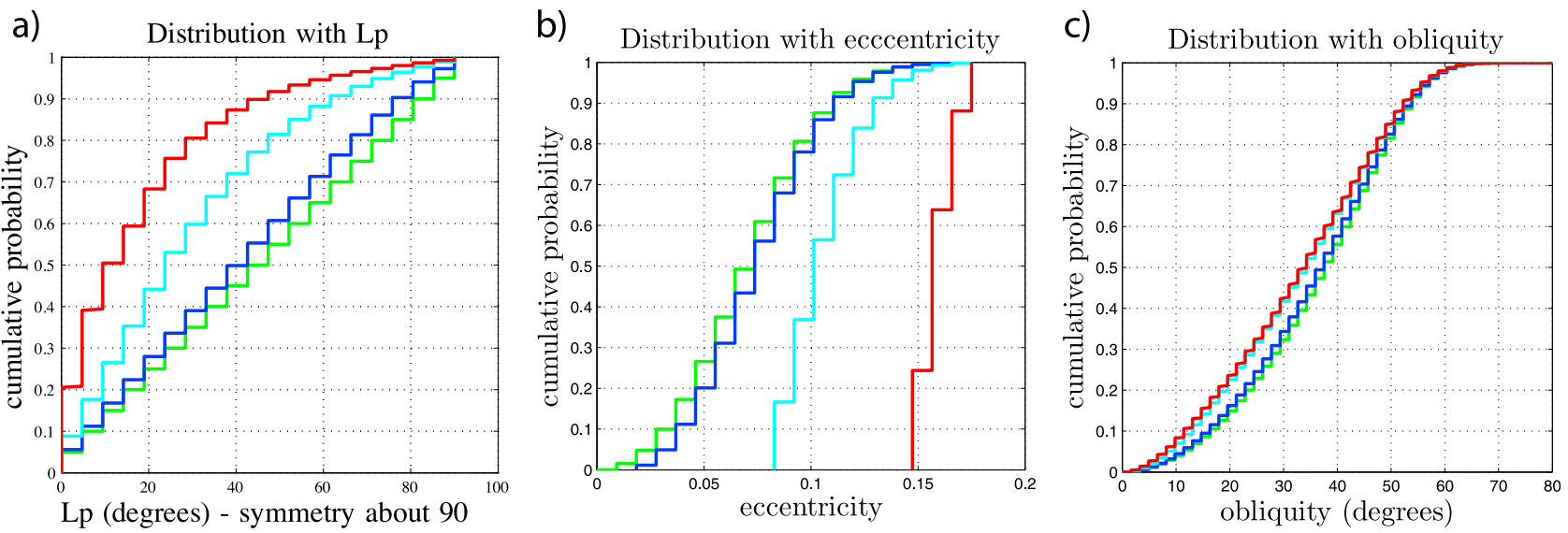

Figure 12. Self-normalized probability density functions for the subset of sampled orbital conditions that produce melt. (a) Longitude of perihelion, (b) eccentricity, and (c) obliquity. In all cases, albedo is 0.28 , and age is $1.0 \mathrm{Ga}$ (other albedos and ages have very similar probability density function (pdf) shapes, although maximum temperatures differ). The cyan lines correspond to $273 \mathrm{~K}$ (melting), and the other colors are green (all temperatures), blue (268 K), and red (278 K).

the peak solar flux. Increasing obliquity narrows the seasonal window during which the sun rises high enough in the equatorial sky for melting to occur. Therefore, the probability of aligning with perihelion is reduced and so the chance of a melting event at high obliquity is lower.

[69] This distribution is almost exactly a ranking in peak solar luminosity, and (for low thermal inertia surfaces) is not sensitive to our model assumptions.

[70] 3. Using slightly less optimistic assumptions in the energy balance approach (humidity of 0.25 and albedo 0.35 ), the minimum SW flux for melting rises to $882 \mathrm{~W}$. This is unachievable at Mars. For comparison, the sunlight striking the top of the atmosphere above North Greenland, $80^{\circ} \mathrm{N}$, at summer solstice during the melt season is $730 \mathrm{~W}$. The strength of the evaporative cooling term at low pressures strongly suppresses snowpack melting. Evaporative cooling may not be relevant for understanding the melting of small quantities of snow that is in contact with nonvolatile soil, and small quantities may be all that is necessary to redistribute mobile elements and to form crusts in the global soil [Amundson et al., 2008; Arvidson et al., 2010]. However, this cannot account for runoff generation and channel formation. Adding $\mathrm{CO}_{2}$ pressure quickly damps evaporative cooling, but also increases the magnitude of sensible heat transfer to the atmosphere. There is a minimum in cooling at intermediate pressures [Hecht, 2002], but this may suppress localized precipitation.

[71] The problem is exacerbated by the threshold processes linking melting to erosion. To generate runoff, melting must outpace the sum of infiltration, sublimation and refreezing. If erosion is to occur, melt-fed streams must be deep and fast enough that their basal traction exceeds the threshold for bed grain motion.

[72] For Early Mars, this dilemma can probably only be resolved by an early orbital state with a smaller semimajor axis or larger eccentricity than the current one; a thicker $\mathrm{CO}_{2} /$ $\mathrm{H}_{2} \mathrm{O}$ atmosphere; or adding non- $\mathrm{CO}_{2}$ greenhouse gases. In summary, our models do suggest a requirement for a different global climate state if localized precipitation is to lead to substantial runoff on gentle slopes on Early Mars, but this is only necessary to bring temperatures back up to the level of contemporary Mars: melting probabilities with present-day solar luminosity are large (Figure 13). To counteract the effect of the Faint Young Sun (FYS) on mean Mars surface temperature at $3.5 \mathrm{Ga}$, the required greenhouse warming is approximately

$$
\Delta T_{\text {fys }}=\left(1-0.77^{0.25}\right) T_{\mathrm{M}} \approx 13 \mathrm{~K}
$$

(with Mars average surface temperature $T_{\mathrm{M}} \sim 210 \mathrm{~K}$; the luminosity at $3.5 \mathrm{Ga}$ is from Bahcall et al. [2001]). This is a relatively modest requirement. It does not hold for impactinduced precipitation because snow falling on hot ejecta will melt provided that atmospheric pressure is above the triple point.

\section{Prospectus and Discussion}

[73] Our model shows lake storm ice forming at terrestrial cirrus cloud temperatures $>200 \mathrm{~K}$, which because of the higher water vapor mixing ratio is warmer than modern Mars cloud forming temperatures $\leq 185 \mathrm{~K}$. Recent laboratory experiments [Iraci et al., 2010] show that ice nucleation at $\mathrm{T} \leq 185 \mathrm{~K}$ requires greater supersaturations than previously thought, while confirming that the MRAMSCARMA parameterization of the critical supersaturation at the higher ice nucleation temperatures observed in our simulation is adequate.

[74] We have focused on ephemeral open water lakes in this study, but this is not the only way of getting water into the atmosphere. Fumaroles and rootless cones inject vapor to the atmosphere, but their efficiency has not been as well studied as that of a wind-stirred lake surface [Zeng et al., 1998]. Gas-charged fountains may inject vapor during the early stages of outflow channel formation [Bargery and Wilson, 2010]. The mass flux we obtain in even the smallest simulation greatly exceed the greatest spring discharges on Earth. Leads in lake ice may allow deep convection to continue after the majority of the lake surface has frozen over. 
a) Annual melting probability

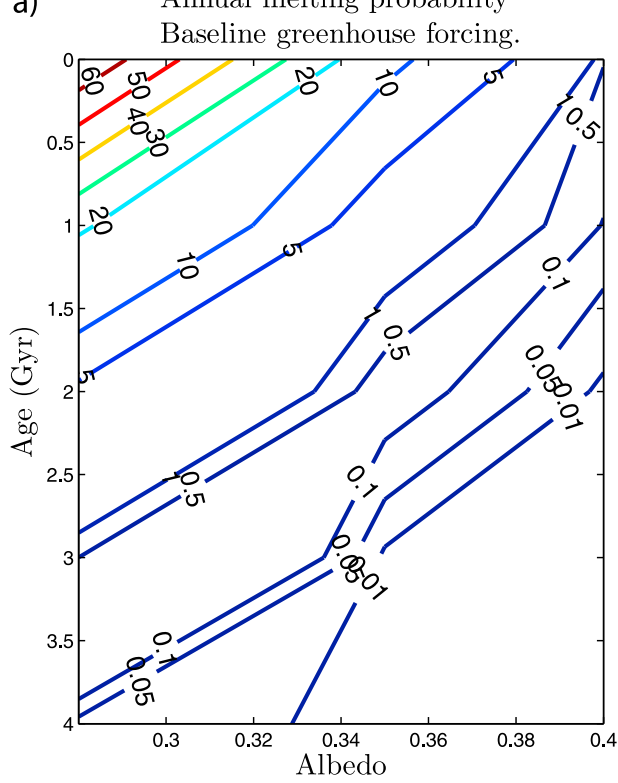

b) Annual melting probability $+6 \mathrm{~K}$ greenhouse forcing.

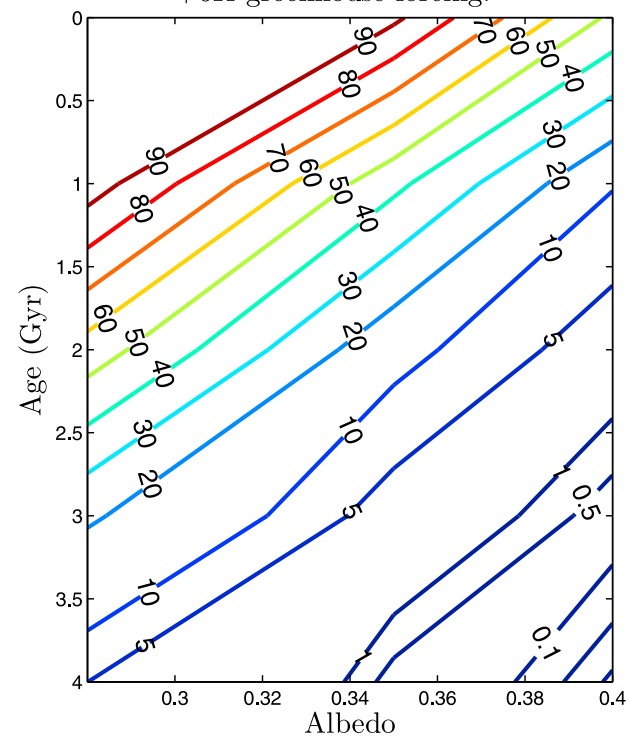

Figure 13. Contoured probability (percent) of melting of rapidly emplaced equatorial precipitation as a function of albedo and solar luminosity. (a) An atmosphere similar to today; (b) an atmosphere with $6 \mathrm{~K}$ additional greenhouse forcing. In the case of impact-induced precipitation, snow falling on hot ejecta will melt regardless of orbital conditions.

\subsection{Geomorphic Paleobarometer?}

[75] Cold lakes at 1 bar on Earth do not produce vigorous storms, with convection and precipitation in a dry background atmosphere (Figure 14); cold lakes at 12 mbar on Mars do, at least in our model. Therefore there is a threshold atmospheric pressure, between 12 mbar and 1 bar, below which cold lakes on Mars can induce convective storms and localized precipitation (orange line in Figure 1). We speculate this pressure is $\sim 10^{2}$ mbar, because this is the pressure at which a $273 \mathrm{~K}$ lake on Mars produces the same buoyancy flux as $299 \mathrm{~K}$ on Earth. $299 \mathrm{~K}$ is the lower limit of the tropical sea surface temperatures that on today's Earth are associated with deep convection [Emanuel, 1994]. A preliminary run at 20x present-day pressure ( $\sim 120$ mbar) showed significant suppression of the buoyant plume, with limited localized precipitation. If a past landform on Mars could be conclusively shown to result from localized, lake-induced precipitation, that would suggest a low atmospheric pressure $\left(\leq 10^{2} \mathrm{mbar}\right)$ at the time it formed. We investigate one set of candidate landforms in paper 2 , but because of geological ambiguities it does not reach the "conclusive" standard.

[76] If the vapor injection mechanism is a fumarole or gascharged fountain rather than a lake surface, then the ability to set a paleopressure constraint goes away. The potentially much higher injection rate can overcome the dilution by the thicker atmosphere.

\subsection{Applications to the Late Hesperian and Amazonian Sedimentary Record}

[77] One motivation for our localized precipitation work is to understand Late Hesperian and Amazonian fluvial features which are widespread, although rare, on the Martian surface (Figure 15 and paper 2). They postdate the global decline in valley formation, aqueous mineralization and erosion rates near the Noachian-Hesperian boundary. Therefore, localized processes are a priori a reasonable explanation for these fluvial features. Unusual microclimates (such as nearby steep slopes) may explain some of the features [Fassett et al., 2010], but those on the Valles Marineris plateau and at Mojave Crater suggest localized precipitation (Figure 15 and Mangold et al. [2008] and paper 2).

[78] Impact-induced precipitation has been proposed to explain fluvial fans at Mojave Crater, but not yet modeled [Williams and Malin, 2008]. Mojave is a fresh crater whose inner terraces are dissected by channelized fans that drain hillslopes. The young fans are very rare in the region surrounding the crater, suggesting that the Mojave impact triggered the fluvial activity that formed the fans [Williams and Malin, 2008]. Several other Amazonian craters show Mojave-like fans, but they are more degraded (e.g., PSP 007447_1995 in Tartarus and PSP_008669_1905 in Isidis). Mojave has been described as a "Rosetta Stone" for decoding impact-associated fluvial features on Mars, because it is relatively young and records with high fidelity processes that are degraded in the ancient record [Segura et al., 2002; Segura et al., 2008; Senft and Stewart, 2008; Toon et al., 2010].

\subsection{Can Localized Precipitation Explain Noachian Erosion?}

[79] Early Mars' geomorphic record strongly suggests that long-lived and regional/global precipitation contributed to Noachian erosion, but it is also consistent with a role for localized precipitation. The well-dated Late Noachian-Early Hesperian [Fassett and Head, 2008b; Hynek et al., 2010] peak in valley formation on Mars includes some integrated drainage networks extending over thousands of kilometers that appear to have formed over a long period of time relative to crater formation [e.g., Barnhart et al. [2009]. Because localized precipitation on a cold planet is almost always 


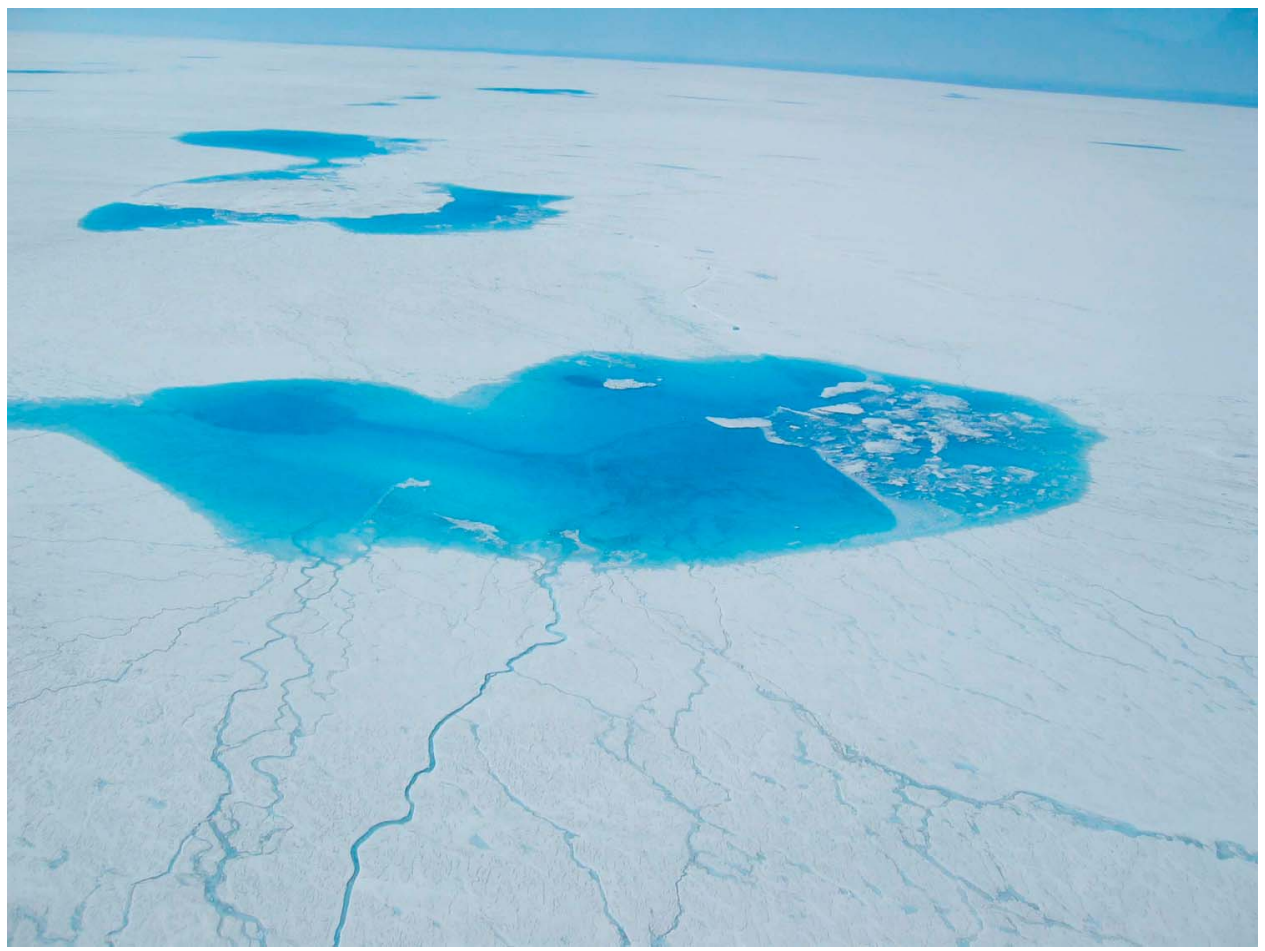

Figure 14. Seasonal supraglacial lakes on Greenland ice sheet. Note absence of clouds and precipitation at $1 \mathrm{bar}$, and high drainage density of meandering, snowmelt-fed channels running into lake. Largest lake is $4.5 \mathrm{~km}$ across. (Image used with kind permission of I. Joughin, University of Washington Polar Science Center.)

short-lived precipitation (section 1), these findings are not consistent with the model developed in this paper. In addition to this timescale problem, the rapid discharges and short formation timescales required to form some valley networks and deltas are at best marginally compatible with snowmelt [Kraal et al., 2008; Kleinhans et al., 2010] and suggest ejecta dewatering or rain phase precipitation. (Atmospheric liquid water aerosol is currently not included in our model.)

[80] On the other hand, the majority of drainage systems on Early Mars are poorly integrated and localized, including most infilled crater floors and eroded crater rims. Inspired by observations at Mojave Crater [Williams and Malin, 2008], and supported by the results of the idealized model presented here, we suggest that localized precipitation is relevant to understanding these systems. Mars' deuterium-hydrogen ratio indicates that Mars has lost water over time [Jakosky, 1991]. Therefore, crater lakes resulting from impacts into icy targets, wet-based ice sheets and lava-ice interactions would all have been more common on ancient Mars, and could serve as localized vapor sources. An Early Mars GCM with water sources at the valley-associated crater lakes shows precipitation only near the lakes and at planetary cold traps, consistent with our mesoscale results [Soto et al., 2010].

[81] Any hypothesis for Early Mars erosion should explain the transition from significant crater infilling and crater rim erosion prior to the Noachian-Hesperian boundary, to minimal erosion in the Middle to Late Hesperian and Amazonian (as documented by, for example, Golombek et al. [2006], Forsberg-Taylor et al. [2004], Boyce and Garbeil [2007], Howard et al. [2005], Irwin et al. [2005], and Moore and Howard [2005]). In a localized precipitation scenario, this would correspond to a change in planetary target properties: an ice-rich crust before the erosional transition, and an icepoor crust afterward [Grimm and Painter, 2009].

[82] For impacts into a planetary crust containing buried ice layers, models suggest that fast moving ice-rich debris flows cause crater infilling in the minutes after impact [Senft and Stewart, 2008]. Therefore, we focus on relatively late stage, relatively prolonged (hours to millenia) erosion of the inner slope of the crater rim.

[83] Energy balance suggests that it is physically possible for localized precipitation to contribute to increased Noachian crater rim erosion. The energy source for the system is the heat of shocked target material. If the vapor source close to the crater center (fumarole, geyser or lake) can mine heat from deep within the shocked material, a sustained vapor source for years is possible, but the interval over which snow melts on contact with fresh ejecta on the rim is limited by conductive cooling of the surface boundary layer. However, if snowmeltfueled erosion removes the chilled boundary layer, hot material will again be exposed and melting can resume. Therefore, positive feedback between erosion and melting can sustain snowmelt-driven erosional activity on the crater rim. Snow can mine heat from deeper within the ejecta blanket provided that

$$
\left(T_{\mathrm{b}}-273.15\right) c_{\mathrm{b}}>\frac{W t}{R k}\left(L_{\mathrm{m}}+\left(273.15-T_{\mathrm{sn}}\right) c_{\mathrm{sn}}\right)
$$

where $W t / R k$ is the water:rock ratio required for erosion, $L_{\mathrm{m}}$ is the latent heat of melting, $T_{\mathrm{sn}}$ is snow temperature, and $c_{\text {sn }}$ is snow heat capacity.

[84] Ejecta blanket thickness is variable but lunar scalings suggest craters $>160 \mathrm{~km}$ diameter have ejecta $>0.6 \mathrm{~km}$ thick at their rim [McGetchin et al., 1973]. Therefore, if ejecta 


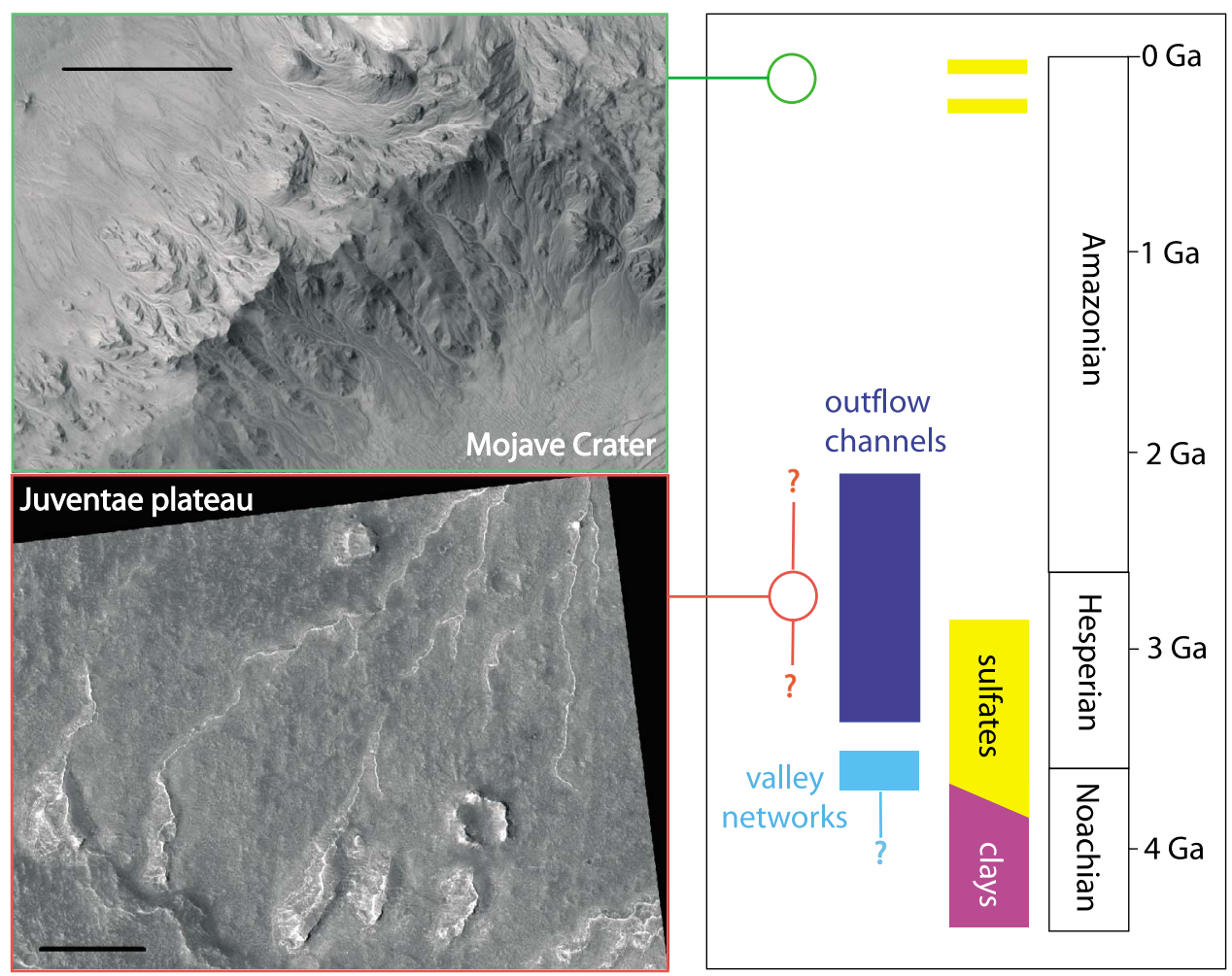

Figure 15. Primary motivation for this study: two geological settings where fluvial activity postdates the Late Noachian-Early Hesperian acme of channel formation and there is a candidate vapor source nearby. Scale bars are $500 \mathrm{~m}$. Green box indicates subkilometer fans resembling alluvial fans at Mojave Crater, which may be a recent impact into icy ground $\left(7.9^{\circ} \mathrm{N}, 326.6^{\circ} \mathrm{E}\right.$, orthorectified HiRISE image PSP 001481_1875). Channels dissect both sides of 100-200 m tall ridge, and channel heads are found $<20 \overline{\mathrm{m}}$ from ridgeline. Red box indicates inverted streams on plateau near Juventae Chasma $\left(4.3^{\circ} \mathrm{S}, 296.7^{\circ} \mathrm{E}\right.$, orthorectified HiRISE image PSP_003223_1755). Negligible post-Noachian erosion over most of the rest of the planet indicates that such events were localized. Sources for stratigraphic context are Hartmann [2005] (absolute ages), Murchie et al. [2009] (clay and sulfate stratigraphy), Carr and Head [2010] (age of outflow channels), Fassett and Head [2008b] (age of valley networks), Massé et al. [2010] and Mangold et al. [2010] (existence of young sulfates), and Le Deit et al. [2010] (age of Juventae plateau channels).

temperature exceeds $900 \mathrm{~K}$, snow is continuously supplied at $1.25 \mathrm{~mm} \mathrm{~h}^{-1}$ as found in our simulations, and the majority of eroded material is removed by debris flows with a $W / R$ of 1.5 , condition (14) is satisfied, and $>0.6 \mathrm{~km}$ material can be eroded from the inner slope of the crater rim by localized precipitation within a decade.

[85] This is directly relevant to three of the final four Mars Science Laboratory candidate landing sites. Gale $(155 \mathrm{~km}$ diameter), Holden (155 km diameter), and Eberswalde (65 km diameter; immediately NE of Holden), because all three have deeply dissected rims showing evidence for aqueous transport of material from the rim to the crater floor [Anderson and Bell, 2010; Moore and Howard, 2005; Rice and Bell, 2010]. (A recent analysis of alluvial fans in Far Western Tyrrhena Terra [Williams et al., 2011] suggests traction-dominated flows with $\mathrm{W} / \mathrm{R} \gg 1.5$. This would be incompatible with our proposed positive feedback.)

\section{Conclusions}

[86] From this study the following conclusions may be made.

[87] 1. A low-pressure lake effect creates deep convection, rapid updrafts, and intense precipitation above cold liquid water surfaces on Mars. On Earth, because of much higher atmospheric pressure, this requires tropical temperatures.

[88] 2. We use MRAMS to simulate lake storms on Mars. The modeled storms have updraft velocities and plume heights which exceed the intensity of the strongest recorded thunderstorms on Earth.

[89] 3. The fraction of vapor that is trapped near the vapor source as localized precipitation increases with lake size.

[90] 4. The localized greenhouse effect of the released water vapor is too weak to cause melting of the snow.

[91] 5. Melting of equatorial, rapidly emplaced localized snow with the albedo of dust is possible for a subset of orbital conditions, even with the present-day weak greenhouse effect.

[92] 6. Assuming that transient lakes on Mars are uncorrelated with orbital forcing, melting of rapidly emplaced localized precipitation is more likely than melting of precipitation that has been emplaced in equilibrium with orbital conditions.

[93] 7. Taken together, localized storms, rapidly emplaced localized precipitation, and favorable orbital conditions are a working hypothesis for (at least part of) the erosion and 
channel formation observed on premodern Mars. This is an alternative to regional/global precipitation.

\section{Appendix A: Methods}

[94] The fully compressible dynamical core of MRAMS is derived from the terrestrial RAMS code [Mahrer and Pielke, 1976]. A cloud microphysical scheme derived from the Community Aerosol and Radiation Model for Atmospheres (CARMA) was recently added to MRAMS by T.I. Michaels. This cloud microphysics scheme has been used to successfully reproduce spacecraft observations of low-latitude clouds downwind of the Tharsis Montes and Olympus Mons [Michaels et al., 2006]. A recent description of MRAMS capabilities is given by Michaels and Rafkin [2008b]. For the runs described in this paper, we use 20 bins in grain size for water ice aerosol. Minimum particle radius is $72.1 \mathrm{~nm}$ and the bins increase in mass with a fixed mass ratio of 7.2. For dust aerosol, we use 8 bins in grain size. Minimum particle radius is $50 \mathrm{~nm}$ and the bins increase in mass with a fixed mass ratio of (again) 7.2.

[95] We made minimal modifications to the MRAMS v.2.5-01 code to allow for surface liquid water. Liquid water microphysics is not included. Water vapor thermodynamics are included in the energy equation, but water vapor is not included in the mass and momentum equations; that is, we ignore pressure and virtual temperature effects. We do not permit dynamic dust lifting at the mesoscale.

[96] We used four grids with the outermost being hemispheric and a horizontal resolution of $\sim 5.9 \mathrm{~km}$ on the inmost grid. Output was sampled every 1/24 sol ( 3699 s), or "Mars hour." We assume that this frequency, limited by available disk space, is enough to capture model behavior; for example, we refer to the warmest of 24 samples during a sol as the “day's maximum temperature." The time step varied between runs but was never more than $3.75 \mathrm{~s}$ on the inmost grid.

[97] The season is southern summer ( $\mathrm{Ls} \sim 270^{\circ}$ ) for the runs, and boundary conditions are from the NASA Ames MGCM, version 2.1. We use present-day orbital conditions.

[98] Our spinup procedure included 24 Mars hours with no vapor release from the lake, 3 Mars hours with vapor release but cloud microphysics off, and the remainder of the run with aerosol microphysics on. We observed that obvious spin-up transients had died away by the end of day 3. Snow albedo feedback was not considered, but would tend to increase the intensity of convergence and convective intensity by increasing the temperature gradient between land and lake.

[99] Acknowledgments. We thank Teresa Segura, Sarah Stewart, Charlie Barnhart, David Romps and Max Rudolph for useful suggestions, Keith Harrison and Bob Grimm for commenting on the manuscript, and Mark Marley for correcting an omission. This work made use of GRaDs scripts by Bin Guan and Chihiro Kodama. We made use of the European Mars Climate Database v4.3. We acknowledge support from Teragrid allocation TGEAR100023, NASA Science Mission Directorate grants NNX08AN13G and NNX09AN18G, and NASA grants to SwRI which funded cloud microphysics capabilities.

\section{References}

Amundson, R., et al. (2008), On the in situ aqueous alteration of soils on Mars, Geochim. Cosmochim. Acta, 72, 3845-3864, doi:10.1016/j.gca. 2008.04.038.
Anderson, R.B., and J.F. Bell III (2010), Geologic mapping and characterization of Gale Crater and implications for its potential as a Mars Science Laboratory landing site, Mars, 5, 76-128, doi:10.1555/mars.2010.0004. Andrews-Hanna, J. C., and R. J. Phillips (2007), Hydrological modeling of outflow channels and chaos regions on Mars, J. Geophys. Res., 112, E08001, doi:10.1029/2006JE002881.

Arvidson, R. E., et al. (2010), Spirit Mars Rover Mission: Overview and selected results from the northern Home Plate Winter Haven to the side of Scamander crater, J. Geophys. Res., 115, E00F03, doi:10.1029/ 2010JE003633.

Bahcall, J. N., et al. (2001), Solar models: Current epoch and time dependences, neutrinos, and helioseismological properties, Astrophys. J., 555, 990-1012, doi:10.1086/321493.

Bargery, A. S., and L. Wilson (2010), Dynamics of the ascent and eruption of water containing dissolved $\mathrm{CO}_{2}$ on Mars, J. Geophys. Res., 115, E05008, doi:10.1029/2009JE003403.

Barnhart, C. J., A. D. Howard, and J. M. Moore (2009), Long-term precipitation and late-stage valley network formation: Landform simulations of Parana Basin, Mars, J. Geophys. Res., 114, E01003, doi:10.1029/ 2008JE003122.

Boyce, J. M., and H. Garbeil (2007), Geometric relationships of pristine Martian complex impact craters, and their implications to Mars geologic history, Geophys. Res. Lett., 34, L16201, doi:10.1029/2007GL029731.

Brock, B. W., I. C. Willis, and M. J. Sharp (2006), Measurement and parameterization of aerodynamic roughness length variations at Haut Glacier d'Arolla, Switzerland, J. Glaciol., 52, 281-297, doi:10.3189/ 172756506781828746

Carr, M. H., and J. W. Head III (2003), Basal melting of snow on early Mars: A possible origin of some valley networks, Geophys. Res. Lett., 30(24), 2245, doi:10.1029/2003GL018575

Carr, M. H., and J. W. Head (2010), Geologic history of Mars, Earth Planet. Sci. Lett., 294, 185-203, doi:10.1016/j.eps1.2009.06.042.

Carr, M. H., and M. C. Malin (2000), Meter-scale characteristics of Martian channels and valleys, Icarus, 146, 366-386, doi:10.1006/icar.2000.6428.

Clow, G. D. (1987), Generation of liquid water on Mars through the melting of a dusty snowpack, Icarus, 72, 95-127, doi:10.1016/0019-1035(87) 90123-0.

Clow, G. D., and R. B. Haberle (1990), Free convection in the Martian atmosphere, Lunar Planet. Sci., 21, Abstract 210.

Conway, S. J., M. P. Lamb, M. R. Balme, M. C. Towner, and J. B. Murray (2011), Enhanced runout and erosion by overland flow at low pressure and sub-freezing conditions: Experiments and application to Mars, Icarus, 211, 443-457, doi:10.1016/j.icarus.2010.08.026.

Dundas, C. M., and S. Byrne (2010), Modeling sublimation of ice exposed by new impacts in the Martian mid-latitudes, Icarus, 206, 716-728, doi:10.1016/j.icarus.2009.09.007.

Emanuel, K. A. (1994), Atmospheric Convection, Oxford Univ. Press, Oxford, U. K

Fassett, C. I., and J. W. Head III (2008a), The timing of Martian valley network activity: Constraints from buffered crater counting, Icarus, 195, 61-89, doi:10.1016/j.icarus.2007.12.009.

Fassett, C. I., and J. W. Head III (2008b), Valley network-fed, open-basin lakes on Mars: Distribution and implications for Noachian surface and subsurface hydrology, Icarus, 198, 37-56, doi:10.1016/j.icarus.2008. 06.016

Fassett, C. I., et al. (2010), Supraglacial and proglacial valleys on Amazonian Mars, Icarus, 208, 86-100, doi:10.1016/j.icarus.2010.02.021.

Forget, F., et al. (2006), Formation of glaciers on Mars by atmospheric precipitation at high obliquity, Science, 311, 368-371, doi:10.1126/science. 1120335

Forsberg-Taylor, N. K., A. D. Howard, and R. A. Craddock (2004), Crater degradation in the Martian highlands: Morphometric analysis of the Sinus Sabaeus region and simulation modeling suggest fluvial processes, J. Geophys. Res., 109, E05002, doi:10.1029/2004JE002242.

Garrett, J. R. (1992), The Atmospheric Boundary Layer, Cambridge Univ. Press, Cambridge, U. K.

Golombek, M. P., et al. (2006), Erosion rates at the Mars Exploration Rover landing sites and long-term climate change on Mars, J. Geophys. Res., 111, E12S10, doi:10.1029/2006JE002754.

Greeley, R., and J. D. Iverson (1989), Wind as a Geological Process on Earth, Mars, Venus and Titan, Cambridge Univ. Press, Cambridge, U. K. Grimm, R. E., and S. L. Painter (2009), On the secular evolution of groundwater on Mars, Geophys. Res. Lett., 36, L24803, doi:10.1029/ 2009GL041018.

Gulick, V. C., and V. R. Baker (1989), Fluvial valleys and Martian paleoclimates, Nature, 341, 514-516, doi:10.1038/341514a0.

Haberle, R. M., J. B. Pollack, J. R. Barnes, R. W. Zurek, C. B. Leovy, J. R. Murphy, H. Lee, and J. Schaeffer (1993), Mars atmospheric dynamics as simulated by the NASA Ames General Circulation Model: 1 . The zonal- 
mean circulation, J. Geophys. Res., 98, 3093-3123, doi:10.1029/ 92JE02946.

Hardy, B. (1998), ITS-90 formulations for vapor pressure, frostpoint temperature, dewpoint temperature, and enhancement factors in the range -100 to $+100 \mathrm{C}$, paper presented at Third International Symposium on Humidity and Moisture, Natl. Phys. Lab., Teddington, U. K.

Harrison, K. P., and R. E. Grimm (2008), Multiple flooding events in Martian outflow channels, J. Geophys. Res., 113, E02002, doi:10.1029/ 2007JE002951.

Hartmann, W. K. (2005), Martian cratering 8: Isochron refinement and the chronology of Mars, Icarus, 174, 294-320, doi:10.1016/j.icarus.2004.11. 023.

Hecht, M. H. (2002), Metastability of liquid water on Mars, Icarus, 156, 373-386, doi:10.1006/icar.2001.6794.

Howard, A. D., J. M. Moore, and R. P. Irwin III (2005), An intense terminal epoch of widespread fluvial activity on early Mars: 1. Valley network incision and associated deposits, J. Geophys. Res., 110, E12S14, doi:10.1029/2005JE002459.

Hudson, T. L., O. Aharonson, N. Schorghofer, C. B. Farmer, M. H. Hecht, and N. T. Bridges (2007), Water vapor diffusion in Mars subsurface environments, J. Geophys. Res., 112, E05016, doi:10.1029/ 2006JE002815

Hynek, B. M., M. Beach, and M. R. T. Hoke (2010), Updated global map of Martian valley networks and implications for climate and hydrologic processes, J. Geophys. Res., 115, E09008, doi:10.1029/2009JE003548.

Ingersoll, A. (1970), Mars: occurrence of liquid water, Science, 168, 972-973, doi:10.1126/science.168.3934.972.

Iraci, L. T., B. D. Phebus, B. M. Stone, and A. Colaprete (2010), Water ice cloud formation on Mars is more difficult than presumed: Laboratory studies of ice nucleation on surrogate materials, Icarus, 210, 985-991, doi:10.1016/j.icarus.2010.07.020.

Irwin, R. P., A. D. Howard, R. A. Craddock, and J. M. Moore (2005), An intense terminal epoch of widespread fluvial activity on early Mars: 2. Increased runoff and paleolake development, J. Geophys. Res., 110, E12S15, doi:10.1029/2005JE002460.

Jakosky, B. (1991), Mars volatile evolution: Evidence from stable isotopes, Icarus, 94, 14-31, doi:10.1016/0019-1035(91)90138-J.

Kite, E. S., S. C. R. Rafkin, T. I. Michaels, and M. Manga (2010), Mesoscale simulation of atmospheric response to chaos formation, Lunar Planet. Sci., 41, Abstract 1171.

Kleinhans, M. G., H. E. van de Kasteele, and E. Hauber (2010), Palaeoflow reconstruction from fan delta morphology on Mars, Earth Planet. Sci. Lett., 294, 378-392, doi:10.1016/j.epsl.2009.11.025.

Kraal, E. R., M. van Dijk, G. Postma, and M. G. Kleinhans (2008), Martian stepped-delta formation by rapid water release, Nature, 451, 973-976, doi:10.1038/nature06615.

Laskar, J., et al. (2004), Long term evolution and chaotic diffusion of the insolation quantities of Mars, Icarus, 170, 343-364, doi:10.1016/j. icarus.2004.04.005.

Le Deit, L., et al. (2010), Morphology, stratigraphy, and mineralogica composition of a layered formation covering the plateaus around Valles Marineris, Mars: Implications for its geological history, Icarus, 208, 684-703, doi:10.1016/j.icarus.2010.03.012.

Lewis, S. R., et al. (1999), A climate database for Mars, J. Geophys. Res., 104, 24,177-24,194, doi:10.1029/1999JE001024.

Liu, J., M. I. Richardson, and R. J. Wilson (2003), An assessment of the global, seasonal, and interannual spacecraft record of Martian climate in the thermal infrared, J. Geophys. Res., 108(E8), 5089, doi:10.1029/ 2002JE001921.

Lorenz, R. D., et al. (2005), Sea-surface wave growth under extraterrestrial atmospheres: Preliminary wind tunnel experiments with application to Mars and Titan, Icarus, 175, 556-560, doi:10.1016/j.icarus.2004.11.019.

Madeleine, J.-B., et al. (2009), Amazonian northern mid-latitude glaciation on Mars: A proposed climate scenario, Icarus, 203, 390-405, doi:10.1016/j.icarus.2009.04.037.

Mahrer, Y., and R. A. Pielke (1976), Numerical simulation of the airflow over Barbados, Mon. Weather Rev., 104, 1392-1402.

Malin, M. C., et al. (2010), An overview of the 1985-2006 Mars Orbiter Camera science investigation, Mars, 5, 1-60, doi:10.1555/mars.2010. 0001 .

Mangold, N., et al. (2008), Geomorphic study of fluvial landforms on the northern Valles Marineris plateau, Mars, J. Geophys. Res., 113, E08009, doi:10.1029/2007JE002985

Mangold, N., et al. (2010), A Late Amazonian alteration layer related to local volcanism on Mars, Icarus, 207, 265-276, doi:10.1016/j.icarus. 2009.10.015.

Markowski, P., and Y. Richardson (2010), Mesoscale Meteorology in Midlatitudes, John Wiley, Chichester, U. K., doi:10.1002/9780470682104.
Massé, M., et al. (2010), Martian polar and circum-polar sulfate-bearing deposits: Sublimation tills derived from the North Polar Cap, Icarus, 209, 434-451, doi:10.1016/j.icarus.2010.04.017.

McEwen, A., et al. (2007), A closer look at water-related geologic activity on Mars, Science, 317, 1706-1709, doi:10.1126/science.1143987.

McGetchin, T. R., M. Settle, and J. W. Head (1973), Radial thickness variation in impact crater ejecta: Implications for lunar basin deposits, Earth Planet. Sci. Lett., 20, 226-236, doi:10.1016/0012-821X(73)90162-3.

Mellon, M. T., et al. (2000), High-resolution thermal inertia mapping from the Mars Global Surveyor Thermal Emission Spectrometer, Icarus, 148 437-455, doi:10.1006/icar.2000.6503.

Mellon, M. T., et al. (2009), The periglacial landscape at the Phoenix landing site, J. Geophys. Res., 114, E00E06, doi:10.1029/2009JE003418.

Michaels, T. I., and S. C. R. Rafkin (2008a), Meteorological predictions for candidate 2007 Phoenix Mars Lander sites using the Mars Regional Atmospheric Modeling System (MRAMS), J. Geophys. Res., 113 E00A07, doi:10.1029/2007JE003013.

Michaels, T. I., and S. C. R. Rafkin (2008b), MRAMS today-One example of current Mars mesoscale modeling capabilities, paper presented at Third International Workshop on Mars Atmosphere: Modeling and Observations, Lunar and Planet. Inst., Williamsburg, Va.

Michaels, T. I., A. Colaprete, and S. C. R. Rafkin (2006), Significant vertical water transport by mountain-induced circulations on Mars, Geophys. Res. Lett., 33, L16201, doi:10.1029/2006GL026562.

Millour, E., F. Forget, and S. R. Lewis (2008), European Mars Climate Database v4.3 Detailed Design Document, Lab. de Météorol. Dyn., Paris. (Available at http://www-mars.lmd.jussieu.fr/)

Moore, J. M., and A. D. Howard (2005), Large alluvial fans on Mars, J. Geophys. Res., 110, E04005, doi:10.1029/2004JE002352.

Morgan, G. A., et al. (2010), Gully formation on Mars: Two recent phases of formation suggested by links between morphology, slope orientation and insolation history, Icarus, 208, 658-666, doi:10.1016/j.icarus.2010. 02.019

Murchie, S. L., et al. (2009), A synthesis of Martian aqueous mineralogy after 1 Mars year of observations from the Mars Reconnaissance Orbiter, J. Geophys. Res., 114, E00D06, doi:10.1029/2009JE003342.

Pielke, R. A. (2002), Mesoscale Meteorological Modeling, Int. Geophys. Ser., vol. 78, 2nd ed., Academic, San Diego, Calif.

Pielke, R. A., et al. (1992), A comprehensive meteorological modeling system-RAMS, Meteorol. Atmos. Phys., 49, 69-91, doi:10.1007/ BF01025401

Pierrehumbert, R. (2010), The surface energy balance, in Principles of Planetary Climate, pp. 386-431, Cambridge Univ. Press, Cambridge, U. K

Rafkin, S. C. R., R. M. Haberle, and T. I. Michaels (2001), The Mars Regional Atmospheric Modeling System (MRAMS): Model description and selected simulations, Icarus, 151, 228-256, doi:10.1006/icar.2001. 6605

Read, P. L., and S. R. Lewis (2004), The Martian Climate Revisited: Atmosphere and Environment of a Desert Planet, Springer-Praxis, Berlin.

Rice, M. S., and J. F. Bell III (2010), Geologic mapping of the proposed Mars Science Laboratory (MSL) landing ellipse in Eberswalde crater, Lunar Planet. Sci., 41, Abstract 2524.

Richardson, M. I., and A. Soto (2008), Controls on precipitation and aridity for ancient Mars, paper presented at Second Workshop on Mars Valley Networks, Smithson. Inst., Moab, Utah.

Rogers, R. R., and M. K. Yau (1989), A Short Course in Cloud Physics, 3rd ed., Pergamon, Oxford, U. K.

Schorghofer, N. (2010), Fast numerical method for growth and retreat of subsurface ice on Mars, Icarus, 208, 598-607, doi:10.1016/j.icarus. 2010.03.022.

Segura, T. L., O. B. Toon, T. Colaprete, and K. Zahnle (2002), Environmental effects of large impacts on Mars, Science, 298, 1977-1980, doi: $10.1126 /$ science. 1073586

Segura, T. L., O. B. Toon, and T. Colaprete (2008), Modeling the environmental effects of moderate-sized impacts on Mars, J. Geophys. Res., 113, E11007, doi:10.1029/2008JE003147.

Senft, L. E., and S. T. Stewart (2008), Impact crater formation in icy layered terrains on Mars, Meteorit. Planet. Sci., 43, 1993-2013, doi:10.1111/j.1945-5100.2008.tb00657.x.

Shean, D. E. (2010), Candidate ice-rich material within equatorial craters on Mars, Geophys. Res. Lett., 37, L24202, doi:10.1029/2010GL045181.

Smith, M. D. (2002), The annual cycle of water vapor on Mars as observed by the Thermal Emission Spectrometer, J. Geophys. Res., 107(E11), 5115, doi:10.1029/2001JE001522.

Soto, A., and M. I. Richardson (2008), Water at the surface of ancient Mars, paper presented at Second Workshop on Mars Valley Networks, Smithson. Inst., Moab, Utah. 
Soto, A., M. I. Richardson, and C. E. Newman (2010), Global constraints on rainfall on ancient Mars: Oceans, lakes, and valley networks, Lunar Planet. Sci., 41, Abstract 2397.

Sullivan, R., et al. (2000), Results of the Imager for Mars Pathfinder windsock experiment, J. Geophys. Res., 105, 24,547-24,562, doi:10.1029/ 1999JE001234.

Toon, O. B., T. Segura, and K. Zahnle (2010), The formation of Martian river valleys by impacts, Annu. Rev. Earth Planet. Sci., 38, 303-322, doi:10.1146/annurev-earth-040809-152354.

Tritton, D. J. (1988), Physical Fluid Dynamics, Oxford Sci, Oxford, U. K.

Turcotte, D. L., and G. Schubert (2002), Geodynamics, 2nd ed., Cambridge Univ. Press, Cambridge, U. K.

Vincendon, M., F. Forget, and J. Mustard (2010), Water ice at low to midlatitudes on Mars, J. Geophys. Res., 115, E10001, doi:10.1029/ 2010JE003584

Wallace, J. M., and P. V. Hobbs (2006), Atmospheric Science: An Introductory Survey, 2nd ed., Elsevier, Amsterdam.

Weitz, C. M., et al. (2008), Light-toned strata and inverted channels adjacent to Juventae and Ganges chasmata, Mars, Geophys. Res. Lett., 35, L19202, doi:10.1029/2008GL035317.

Williams, R. M. E. (2007), Global spatial distribution of raised curvilinear features on Mars, Lunar Planet. Sci., 38, Abstract 1821.
Williams, R. M. E., and M. C. Malin (2008), Sub-kilometer fans in Mojave Crater, Mars, Icarus, 198, 365-383, doi:10.1016/j.icarus.2008.07.013.

Williams, R. M. E., et al. (2011), Evidence for episodic alluvial fan formation in far western Terra Tyrrhena, Mars, Icarus, 211, 222-237, doi:10.1016/j.icarus.2010.10.001.

Wolff, M. J., and R. T. Clancy (2003), Constraints on the size of Martian aerosols from Thermal Emission Spectrometer observations, J. Geophys. Res., 108(E9), 5097, doi:10.1029/2003JE002057.

Wordsworth, R., F. Forget, and V. Eymet (2010), Infra-red collisioninduced and far-line absorption in dense $\mathrm{CO}_{2}$ atmospheres, Icarus, 210, 992-997, doi:10.1016/j.icarus.2010.06.010.

Zeng, X. B., M. Zhao, and M. E. Dickinson (1998), Intercomparison of bulk aerodynamic algorithms for the computation of sea surface fluxes using TOGA COARE and TAO data, J. Clim., 11, 2628-2644, doi:10.1175/1520-0442(1998)011<2628:IOBAAF >2.0.CO;2.

W. E. Dietrich, E. S. Kite, and M. Manga, Department of Earth and Planetary Science, University of California, 307 McCone Hall M/C 4767, Berkeley, CA 94720, USA. (kite@berkeley.edu)

T. I. Michaels and S. Rafkin, Department of Space Studies, Southwest Research Institute, 1050 Walnut St., Boulder, CO 80302-5142, USA. 